\title{
Article
}

\section{Numerical Analysis of the Effects of using Effervescent Atomization on Solution Precursor Thermal Spraying Process}

\author{
Mahrukh Mahrukh, Arvind Kumar, Seyed Ali Nabavi, Sai Gu, and Ilai Sher \\ Ind. Eng. Chem. Res., Just Accepted Manuscript • DOI: 10.1021/acs.iecr.7b01864 • Publication Date (Web): 08 Sep 2017
}

Downloaded from http://pubs.acs.org on September 25, 2017

\section{Just Accepted}

"Just Accepted" manuscripts have been peer-reviewed and accepted for publication. They are posted online prior to technical editing, formatting for publication and author proofing. The American Chemical Society provides "Just Accepted" as a free service to the research community to expedite the dissemination of scientific material as soon as possible after acceptance. "Just Accepted" manuscripts appear in full in PDF format accompanied by an HTML abstract. "Just Accepted" manuscripts have been fully peer reviewed, but should not be considered the official version of record. They are accessible to all readers and citable by the Digital Object Identifier (DOI®). "Just Accepted" is an optional service offered to authors. Therefore, the "Just Accepted" Web site may not include all articles that will be published in the journal. After a manuscript is technically edited and formatted, it will be removed from the "Just Accepted" Web site and published as an ASAP article. Note that technical editing may introduce minor changes to the manuscript text and/or graphics which could affect content, and all legal disclaimers and ethical guidelines that apply to the journal pertain. ACS cannot be held responsible for errors or consequences arising from the use of information contained in these "Just Accepted" manuscripts. 


\title{
Numerical Analysis of the Effects of using
}

\section{Effervescent Atomization on Solution Precursor}

\section{Thermal Spraying Process}

\author{
"Mahrukh Mahrukh", , Arvind Kumar ${ }^{c}$, Seyed Ali Nabavi ${ }^{a}$, Sai Gu ${ }^{d,}$, Ilai Sher ${ }^{a}$ \\ a School of Energy, Environment \& Agrifood, Cranfield University, College Road, Cranfield, \\ Bedfordshire, MK43 0AL, UK \\ ${ }^{\mathrm{b}}$ Department of Mechanical Engineering, NED University of Engineering \& Technology, \\ University Road, 75270 Karachi, Pakistan \\ ${ }^{\mathrm{c}}$ Department of Mechanical Engineering, Indian Institute of Technology, Kanpur 208016, India \\ d, * Department of Chemical and Process Engineering, Faculty of Engineering and Physical \\ Sciences, University of Surrey, Guildford, GU2 7XH, UK \\ * Corresponding author: Email: sai.gu@surrey.ac.uk, Tel. +44 01483 682676"
}

Published by ACS. This is the Author Accepted Manuscript issued with:Creative Commons Attribution Non-Commercial License (CC:BY:NC 3.0). The final published version (version of record) is available online at DOI:10.1021/acs.iecr.7b01864. Please refer to any applicable publisher terms of use. 


\begin{abstract}
The solution precursor thermal spraying (SPTS) process is used to obtain nano-sized dense coating layers. During the SPTS process, the in situ formation of nanoparticles is mainly dependent on combustion gas-temperature, gas-pressure, gas-velocity, torch design, fuel type, and Oxygen-Fuel $(\mathrm{O} / \mathrm{F})$ mixture ratios, precursor injection feeding ratio and flow rates, properties of fuel and precursor and its concentration, and the precursor droplets fragmentation. The focus of the present work is the numerical study of atomization of pure solvent droplets streams into fine droplets spray using an effervescent twin-fluid atomizer. For better droplet disintegration appropriate atomization techniques can be used for injecting the precursor in the $\mathrm{CH}-2000$ high-velocity oxygen fuel (HVOF) torch. The CFD computations of the SPTS process are essentially required because the internal flow physics of HVOF process cannot be examined experimentally. In this research for the first time, an effervescent twin-fluid injection nozzle is designed to inject the solution precursor into the HVOF torch, and the effects on the HVOF flame dynamics are analyzed. The computational fluid dynamics (CFD) modeling is performed using Linearized Instability Sheet Atomization (LISA) model and validated by the measured values of droplets size distribution at varied Gas-toLiquid flow rate Ratios (GLR). Different nozzle diameters with varied injection parameters are numerically tested, and results are compared to observe the effects on the droplet disintegration and evaporation. It is concluded that the effervescent atomization nozzle used in the $\mathrm{CH}-2000 \mathrm{HVOF}$ torch can work efficiently even with bigger exit diameters and with higher values of viscosity and surface-tension of the solution. It can generate smaller size precursor droplets $(2 \mu \mathrm{m}<\mathrm{d}<20 \mu \mathrm{m})$ that could help in the formation of fine nanostructured coatings.
\end{abstract}

KEYWORDS: Solution precursor thermal spraying process; Effervescent atomization; atomization modeling. 


\section{INTRODUCTION}

In the SPTS process, the size of nanoparticles depends on different constraints containing HVOF flame-temperature, flame-velocity, solution feed-rate, precursor solution concentration, precursor solvent properties (viscosity and surface-tension), precursor injection parameters and atomization of precursor streams ${ }^{1-4}$. Moreover, the droplets' fragmentation is required for water-based precursor solution carrying high solute concentrations to increase process efficiency for producing nano-size dense coating ${ }^{5}$. The fragmentation of solvent can be regulated by spray nozzle design parameters and its liquid injection factors ${ }^{6-8}$.

Numerous investigators have analyzed the phenomena of atomization, and some of the work is underlined here. The theory explained by Castleman ${ }^{9}$ states that aerodynamic interaction between the liquid droplets and pressurized gas cause the atomization of liquids. It will lead to unsteady wave development on the liquid jet surface; thus the pressurized gas strikes the liquid-jet and part of the liquid is detached from the jet forming fine ligaments that finally turns into small-size droplets. The higher gas pressure and velocity will form smaller size ligaments and droplets. The liquid-jet fragmentation is a stepwise process; in which the nearest jet section breaks up by the shedding of liquid films and ligaments. Moreover, secondary breakup occurred in the far field jet fragmentation, wherein the fragmented liquid lumps from the jet are formed by the interaction of higher-velocity gas sprays ${ }^{10}$. Thus, this atomization technique is appropriate for generating smaller size droplets.

The advanced technique of effervescent atomization is known as a twin fluid atomization. In this method, a smaller quantity of gas is inserted into the liquid prior to departure through the orifice to form a bubble mixture containing gas and liquid. When evolving from the spray nozzle's exit, the bubbles quickly grow and fragment the liquid into ligaments then formed finer droplets. This happens due to the pressure differences between the gas and liquid ${ }^{6-8,11-18}$. The advantage of the effervescent atomization's sprays is that it can provide smaller-size droplet even at low injection 
pressures. This method can atomize highly-viscous liquids in spite of the low gas pressure. It works very efficiently when compared with no atomization cases. It is investigated by Jedelsky et al. ${ }^{16}$ that increasing GLR and gas input pressure will lead to a finer spray. However, high GLR and high gas input pressure result in higher energy consumption; therefore optimization is required for the best overall operational efficiency. The droplets size and spread also depend on the feedstock concentration, viscidness, and surface-tension, it has been broadly analyzed in ${ }^{8,15,19,20}$, and not repeated here for brevity.

The numerical modeling of internal and external flow regimes of the effervescent atomization has been performed by some scientists in ${ }^{8,15,16,20-23}$. Esfarjani and Dolatabadi ${ }^{22}$, analyzed that the mixing of gas and liquid can be enhanced by increasing the GLR. Also, the co-annular flow regime inside the effervescent nozzle provides more uniform and stable atomization as compared with lower GLRs. It is also concluded that these types of atomizers can operate independently of liquid physical properties (density and viscosity). This analysis was performed by using a wide-range of varying nanoparticles concentrations for suspension plasma spraying (SPS) process and no significant effects on effervescent atomizer have been detected ${ }^{22}$.

A three-dimensional model was prepared by Qian et al. ${ }^{8}$. This model can analyze the external two-phase flow regimes of the effervescent spray nozzle and the effects of varying injection factors on droplets Sauter Mean Diameter (SMD). Based on broad calculations, and using curve fitting techniques, a fitting formula was developed. This empirical relation can relate the SMD to the effervescent nozzle working conditions comprising the injection pressure, GLR, injector exit orifice diameter, and also the liquid physical properties such as viscidness, and surface-tension. It is shown in this study that liquid viscosity has small effects on droplets size and distribution, thus no significant effects over the atomizer efficiency have been observed even for highly-viscous working fluids. It is also concluded that liquid having smaller density and surface-tension can form finer 
droplet's atomization. They also simulated the effect of atomizer operating conditions on particles characteristics and SPS. Moreover, their model can predict the nanoparticles trajectory, velocity, temperature, and size in the Radio Frequency (RF) SPS process ${ }^{8,13,15,20,24}$.

The spray atomization for low-pressure conditions is experimentally and numerically analyzed by Fung et al. ${ }^{25}$. LISA model from Fluent is used to simulate the primary atomization in nasal spray device and the Taylor Analogy Breakup (TAB) model is utilized to capture secondary breakup of droplets. It is concluded that for low-injection pressure applications from $0.3-$ to- $0.5 \mathrm{MPa}$, the LISA model could successfully predict the spray cone shape and droplets size distribution by controlling liquid sheet constants and spread parameters.

Researchers also studied the SPTS method, some literature is mentioned here for understanding the SPTS process. Chen et al. studied the deposition of Alumina-Zirconia $\left(\mathrm{Al}_{2} \mathrm{O}_{3}-\mathrm{ZrO}_{2}\right)$ ceramic coatings by the SPTS process ${ }^{26}$. Both nano crystalline $\mathrm{ZrO}_{2}$ and amorphous $\gamma-\mathrm{Al}_{2} \mathrm{O}_{3}$ are obtained by the coating characterization. The coatings consist of $2-$ to $-5 \mu \mathrm{m}$ ultrafine splats, some solid particles and some particles with hollow shell structures, and the coating has high-density and thickness of 40 $\mu \mathrm{m}^{26}$

Still, very few scientists have numerically modeled the SPTS process. Modeling of the SPTS process has shown that droplet added in the HVOF jet experience strong shear fragmentation due to higher- relative velocities, hence, producing smaller-secondary droplets ${ }^{26-28}$. Basu and Cetegen ${ }^{27}$ numerically analyzed the liquid feedstock into the HVOF flame jet and observed that smaller-size drops are vanished quickly and give out nanoparticles by quick heating whereas the larger-size drops produce precipitate shells with inside liquid core. It was concluded that coating formed by this method is thicker than the conventional process ${ }^{27}$.

In the present work, different injection nozzles are tested numerically to analyze the effects of droplets disintegration on the SPTS process, based on different research studies highlighted above 
$9,13,15,24,26-29$. This study is only restricted to analyze the effects of pure solvents injection on the SPTS process dynamics, whereas formation and deposition of nanoparticles' are not presented here and its details can be seen in ${ }^{30,31}$. The CFD computations of the SPTS process are essentially required because the internal flow physics of this process cannot be examined experimentally. In this research for the first time, an effervescent twin-fluid injection nozzle (N3) is designed to inject the solution precursor into the HVOF torch, to improve the nanoparticles based coatings. The nozzle $\mathrm{N} 3$ is designed for the $\mathrm{CH}-2000 \mathrm{HVOF}$ torch and compared with the plain-orifice and angular injection nozzles N1 and N2 respectively.

Firstly, the old-injection nozzle (N1) and a new-nozzle (N2) (with some modifications in the oldnozzle) are tested for droplets disintegration inside the SPTS process, (more details can be seen in the latest research paper ${ }^{31}$ ). Secondly, an effervescent atomizer is designed ${ }^{6,8,16}$ for the solution precursor's atomization in the combustion chamber (CC) of the CH-2000 HVOF torch. It was analyzed that disintegration of the liquid feedstock inside HVOF torch is essential for successful nanoparticles dense and thick coatings; as the addition of solvent without atomization resulted in bigger size nanoparticles and may produce porous coatings ${ }^{31}$. Different injection parameters are altered to see the effects on the droplets' disintegration process of the effervescent atomizer. For the first time, various injection nozzles with plain-orifice injection (nozzle N1), angular injection (nozzle N2), and effervescent atomization (nozzle N3) are used to examine the effects on the droplets disintegration and evaporation in the $\mathrm{CH}-2000$ HVOF torch. Furthermore, three different solvents, viz., pure water (P-W), water-ethanol (W-E) mixture (carrying 50\% water and 50\% ethanol by volume) and pure ethanol (P-E) are used to analyze the effects of varied liquid properties on the effervescent atomization process. 


\section{MATERIAL AND METHODS}

\subsection{The SPTS process physics}

This section is included in the present work to understand the overall flow physics during the SPTS process. Whereas it is to be noted that spray flames with particle formation are not investigated here, this study is only limited to inspect the effects of pure solvents addition on the SPTS process dynamics, whereas formation and deposition of nanoparticles' are out of the scope of the present work. The nanoparticles' nucleation process is described schematically in Fig. 1. In the SPTS process, the precursor is fed into the HVOF torch through a central opening. The O/F mixture combusts inside the $\mathrm{CC}$ and provides the heat required for the precursor droplets' evaporation and in situ particle formation (Fig. 1). In the CC-section-I of HVOF torch, the chemical reaction for precursor decomposition starts instantaneously as the droplets interact with the surrounding hot-gas and convert into vapors. The vaporization of the solvent is reliant on the combustion temperature, and under high gas flow rate (GFR), the liquid rapidly boils and increases the rate of evaporation. It is generally stated that a higher evaporation rate will ultimately increase the average particle growth rate $^{32}$.

Formation of nanoparticles starts in the region where the $\mathrm{O} / \mathrm{F}$ combustion gases and precursor vapors get in contact inside the $\mathrm{CC}$, also turbulence mixing occurs near torch's axis, as the solvent drops are injected axially into the $\mathrm{CC}$ through a central hole/opening (Fig. 1). The particles are formed by homogeneous nucleation ${ }^{32}$. In the SPTS process, the nucleation and growth of nanoparticles are significantly affected by the local cooling rate (caused by heat removal due to drops vaporization), vapors/ formed particles' residence time distribution and formed particles' number density (Fig. 1). Moreover, the physical and chemical properties of nanoparticles are dependent on different factors, such as hot gas-temperature, gas-pressure, gas-velocity, HVOF CC and barrel design, $\mathrm{O} / \mathrm{F}$ flow rates and feeding ratio, fuel, and precursor properties ${ }^{26-28}$. Firstly, the 
precursor droplets after being inserted into the HVOF torch, experience numerous processes occurring simultaneously. The first phase is the aerodynamic disintegration, as the slow moving droplets are interacting with the HVOF's dynamic gases and accelerated in the high-velocity gas stream (Fig. 1). Droplets undergo severe deformation and ultimately break up into smaller-sized droplets depending on the droplet initial size and thermo-physical properties of the precursor, and the surrounding gas conditions,

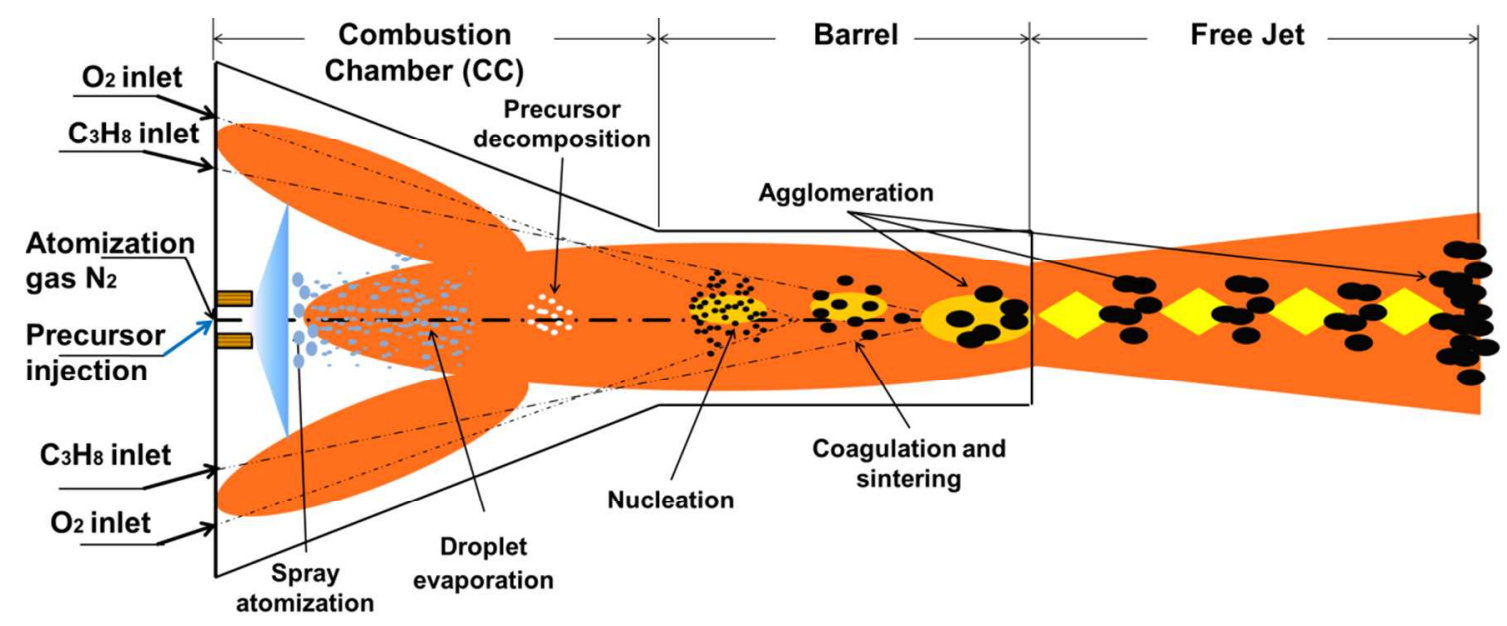

Figure 1. Representation of the SPTS process for nanoparticles formation from ${ }^{31}$

The micron-sized precursor droplets evaporated in $\mathrm{CC}$ and the precursor gas is going through a chemical reaction after which the formation of particles begins (Fig. 1). The high-temperature is required to vaporize the precursor droplets and to form suitable environments for the chemical decomposition. The temperature of HVOF flames varies from 3000-to-4000 K based on the fueltype, $\mathrm{O} / \mathrm{F}$ mixture ratio and operating conditions ${ }^{30,31,33-37}$. Initially, the particles are formed by gasphase nucleation and start growing by coagulation; later, they combine to form larger particles. The rates of coalescence and coagulation would determine the shape of the final product. If sintering rate is faster than the coagulation rate, the formed particles are sphere-shaped. Otherwise, irregularshaped agglomerates are formed ${ }^{32,38}$. 


\subsection{Design and operating conditions of HVOF torch and injection nozzles}

The HVOF torch used for the analysis is the $\mathrm{CH}-2000$ type. The $\mathrm{CH}-2000$ torch is designed and made in Xi' an Jiaotong University, China and more details can be seen in Figs. 1a and 1b in ${ }^{31,37,39-}$ 41. The required quantity of propane $\left(\mathrm{C}_{3} \mathrm{H}_{8}\right)$ and oxygen $\left(\mathrm{O}_{2}\right)$ are fed into the $\mathrm{CH}-2000$ torch (as shown in Figs. 2a, 2b, 2c, also see Table 1); the hot-gases are accelerated in the CC and then flow through the barrel-section towards the torch's exit. Various injection nozzles with plain-orifice injection nozzle N1, angular injection nozzle N2, and effervescent atomization nozzle N3 are used to examine the effects of the droplets fragmentation and vaporization inside HVOF torch ${ }^{37}$. Also, the results are compared to select best injection nozzle for the $\mathrm{CH}-2000$ torch. These three kinds of liquid injection nozzles are designed according to $\mathrm{CH}-2000 \mathrm{HVOF}$ torch requirements and the effects of varied nozzle types on the droplets atomization and vaporization are studied. The design criteria of injection nozzles are based on the available $\mathrm{CH}-2000 \mathrm{HVOF}$ torch, as the internal space available to fit the injection nozzle is limited and two different designs that fit in that limited space are manufactured. In which the first one is an angular injection (named nozzle N2) and the second one is effervescent atomization (named nozzle N3), whereas the actual injection nozzle available is named as N1. The old injection nozzle N1 head (having an exit diameter of $\mathrm{D}_{\text {inj }}=0.5 \mathrm{~mm}$ ) is modified to angular injection nozzle N2 to improve the droplet fragmentation by injecting the droplets into the core of CC (Figs. 2a \& 2b). The nozzle N2 is designed to inject the precursor into the $\mathrm{CC}$ of the $\mathrm{CH}-2000$ torch with an angle of injection $\alpha=60^{\circ}$; it has six holes with diameters of $\mathrm{D}_{\text {inj }}=0.3 \mathrm{~mm}$ (Fig. 2b).

Furthermore, a new effervescent atomization nozzle N3 has been designed for solution precursor atomization based on outside-in design (Figs. $2 \mathrm{c}$ and $2 \mathrm{~d})^{6-8,11-16}$. The effervescent atomization technique is used to create bubbles in the injection nozzle and then spraying it into the HVOFs' CC to get a fine spray of the precursor. In this method, the precursor ejects out from the orifice with an 
internal cavity of gas at angle $\theta\left(\theta\right.$ assumed value $\left.=3^{\circ}\right)$. Due to high-pressure drop between gas and liquid, the gases expand and fragment the liquid into ligaments and generate fine drops ${ }^{6,8,16}$. The nozzle N3 exit diameter $\left(D_{\text {inj }}\right)$ is varied as mentioned in Table 1. Some of the preliminary atomization in the $\mathrm{CC}$ is shown schematically in the Figs. $2 \mathrm{a}, 2 \mathrm{~b}$, and $2 \mathrm{c}$ to compare the old singlefluid (without atomization, N1, N2) and the new twin-fluid (with atomization, N3) injection phenomenon; the detailed results will be analyzed and discussed in subsequent sections.

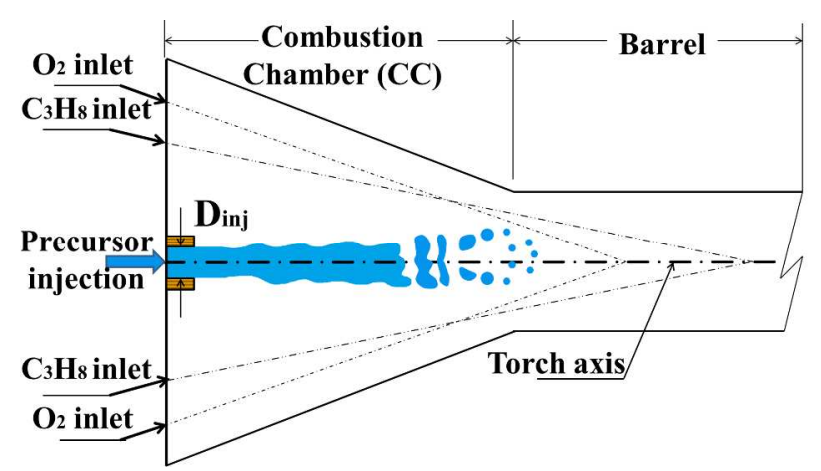

(a)

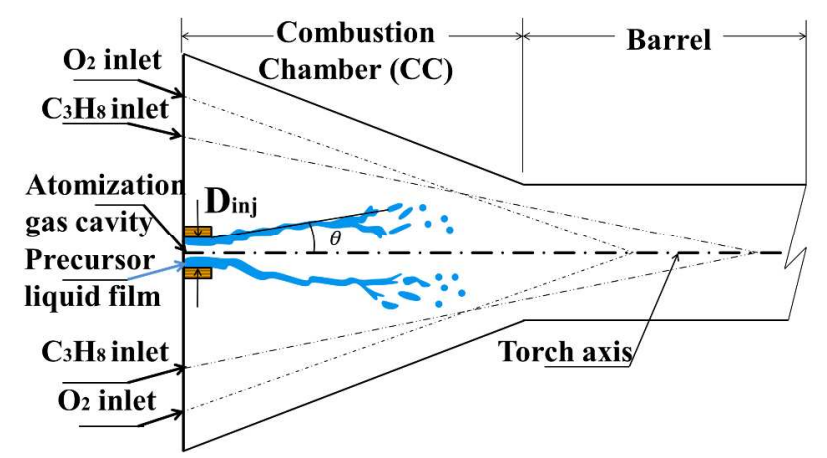

(c)

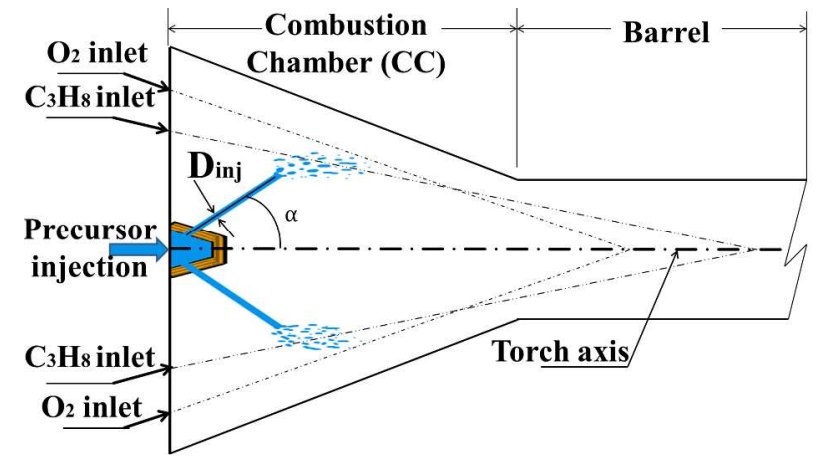

(b)

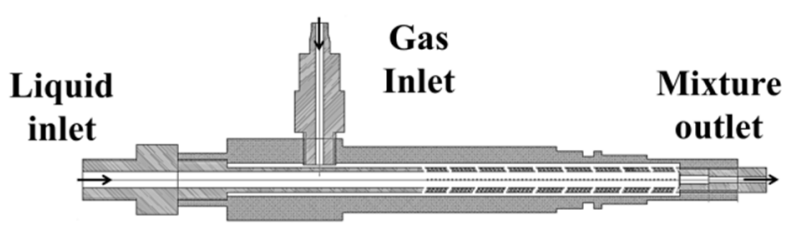

(d)

Figure 2. Representation of precursor injection into the $\mathrm{CH}-2000 \mathrm{HVOF}$ torch (a) plain-orifice nozzle (N1), (b) angular injection nozzle (N2), (c) effervescent atomization nozzle (N3), (d) crosssection view of effervescent-type nozzle (N3) $31,37,42$ 
Table 1. Operating conditions and input parameters for HVOF torch and injection nozzles ${ }^{31,37,39-41}$

\begin{tabular}{ll}
\hline \hline \multicolumn{2}{l}{ Injection parameters for spray in the atmosphere } \\
\hline Water Density $\left(\rho_{\mathrm{w}}\right)$ & $998.2 \mathrm{~kg} / \mathrm{m}^{3}$ \\
Water Viscosity $\left(\mu_{\mathrm{w}}\right)$ & $0.001003 \mathrm{~kg} / \mathrm{m}-\mathrm{s}$ \\
Water Surface-tension $\left(\sigma_{\mathrm{w}}\right)$ & $0.0719 \mathrm{~N} / \mathrm{m}$ \\
Water Mass flow-rate $\left(\mathrm{m}_{\mathrm{W}}\right)$ & $0.00083183 \mathrm{~kg} / \mathrm{s}$ \\
Nozzle-Injection pressure $\left(\mathrm{P}_{\text {inj }}\right)$ & $0.6,0.7,0.8 \mathrm{MPa}$ \\
Nozzle-Injection diameters $\left(\mathrm{D}_{\text {inj }}\right)$ & $0.5,1.0,1.5,2.0 \mathrm{~mm}$ \\
Nitrogen flow-rates $\left(\mathrm{Q}_{\mathrm{gas}}\right)$ & $6,8 \mathrm{and} 101 / \mathrm{min}$ \\
Gas-to-Liquid mass flow rate Ratio $(\mathrm{GLR})$ & $0.0456,0.0912,0.137,0.182,0.228$ \\
\hline \hline Operating conditions and injection parameters for spray in HVOF torch \\
\hline \hline Oxygen flow-rate & $0.007368 \mathrm{~kg} / \mathrm{s}$ \\
Propane flow-rate & $0.001581 \mathrm{~kg} / \mathrm{s}$ \\
Nitrogen flow-rate & $0.001349 \mathrm{~kg} / \mathrm{s}(\mathrm{Case} 1-$ Without Droplet $)$ \\
Pure Water flow-rate $\left(\mathrm{Q}_{\mathrm{P}-\mathrm{W}}\right)$ & $50 \mathrm{ml} / \mathrm{min}$ \\
Pure Ethanol flow-rate $\left(\mathrm{Q}_{\mathrm{P}-\mathrm{E}}\right)$ & $50 \mathrm{ml} / \mathrm{min}$ \\
Water-Ethanol mixture flow-rate $\left(\mathrm{Q}_{\mathrm{W}-\mathrm{E}}\right)$ & $50 \mathrm{ml} / \mathrm{min}$ \\
Solution precursor flow-rate $(\mathrm{N} 3)\left(\mathrm{Q}_{\text {liquid }}\right)$ & 50,100, and $200 \mathrm{ml} / \mathrm{min}$ \\
Nitrogen flow-rates $(\mathrm{N} 3)\left(\mathrm{Q}_{\mathrm{gas}}\right)$ & $81 / \mathrm{min}$ \\
Gas-to-Liquid mass flow-rate Ratio $(\mathrm{N} 3)$ & $0.0456,0.0912,0.182$ \\
Nozzle-Injection diameters $(\mathrm{N} 3)$ & $0.5,1.5,2.0 \mathrm{~mm}$ \\
Nozzle-Injection pressure & $0.7,0.8,0.9,1.0 \mathrm{MPa}$ \\
\hline
\end{tabular}

\subsection{HVOF Flame Temperature measurements (In-house experiments)}

High flame temperatures are required for the evaporation of the precursor solution and nanoparticles formation in the HVOF torch ${ }^{39-41}$. For the validation of the CFD-code, some in-house experiments are performed. During these experiments, the temperature of HVOF flame is measured with and without injection of solution precursor droplets. The data is plotted in the result section-3.2 for the comparison of flame temperatures using different solvents. For setting the combustion inside the HVOF torch the GFRs are selected according to the previous work (Table $\mathbf{1}^{31,37,39-41}$ ) to obtain 
high-temperature flames with supersonic jet outlet velocities. For Case1, the O/F gases are injected into the $\mathrm{CH}-2000$ torch's $\mathrm{CC}$, and shock-diamonds are observed when the HVOF flame is exiting from the torch end. The temperature sensing is performed by using low (K-type) and high (B-type) thermocouples in-house experimentations. In Case2, the $\mathrm{O} / \mathrm{F}$ flow rates remain the same while the nitrogen gas injection is replaced by the liquid injection (see Table 1). For Case2, temperature measurements are repeated by thermocouples. Moreover, three different liquid solvents are fed into the $\mathrm{CH}-2000$ torch successively. P-W injection is named as Case2a, P-E injection as Case2b and WE mixture injection as Case2c. For all the cases the data are gathered and plotted here for combustion model validation (see section-3.2.). It must be noted that the temperature sensing performed by thermocouple has significant errors involved due to radiation, convection, and conduction heat losses ${ }^{43}$, hence in comparison to the actual values of temperature some error/deviation is evident in these measurements. The detailed analysis for model validation is presented in section-3.2.

\subsection{Numerical modeling}

The axisymmetric, two-dimensional grid with 48208 nodes is generated (shown in Fig. 3a) for the model validation. The size of the domain is $0.04 \mathrm{~m} \times 0.250 \mathrm{~m}$, and the mesh is fine near the spray nozzle exit area to capture the atomization details. In an experimental study by Liu et al. ${ }^{7}$, the liquid-water and atomizing gas-nitrogen mixture are sprayed into the atmosphere. The data are gathered for the detailed analysis of droplets sizes at varied GLRs. Moreover, different cases are simulated and validated for the effervescent nozzle with varied GLRs using CFD by Qian et al. ${ }^{15,20}$. In the present numerical work, for model validation, the operating conditions are $\mathrm{P}_{\mathrm{inj}}=0.6 \mathrm{Mpa}$, $\mathrm{D}_{\mathrm{inj}}=4 \mathrm{~mm}, \mathrm{~m}_{\mathrm{w}}=1.6 \mathrm{~kg} / \mathrm{min}$ with varying GLRs from $0.067,0.090,0.132,0.176$ according to the Liu et al. ${ }^{7}$, and Qian et al. ${ }^{15,20}$ case studies. 
Secondly, the axisymmetric two-dimensional grid for the CH-2000 HVOF torch is considered for the numerical simulations of effervescent atomization in the SPTS process (grid size=144300 nodes, shown in Fig. 3b). After simulating HVOF gas dynamics, including combustion and turbulence in the torch, precursor droplets carrying P-W, P-E, and W-E mixture are added axially into the CC through a central opening (Fig. 3b). In the present work, Ansys Fluent (14.5.0) is used to model the gas combustion, turbulence, droplet breakup, heat-up and evaporation in the torch for all numerical simulations ${ }^{37}$. The numerical equations are discretized by second order upwind scheme while the pressure-velocity coupling is solved by the Coupled scheme. The operating conditions and injection properties for the numerical analysis of the CH-2000 HVOF torch are defined in Table $\mathbf{1}^{31,37,39-41}$.

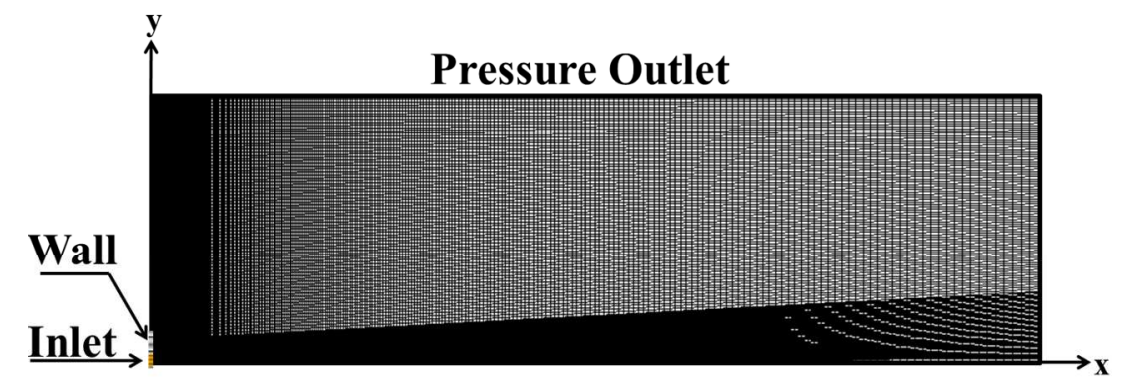

(a)

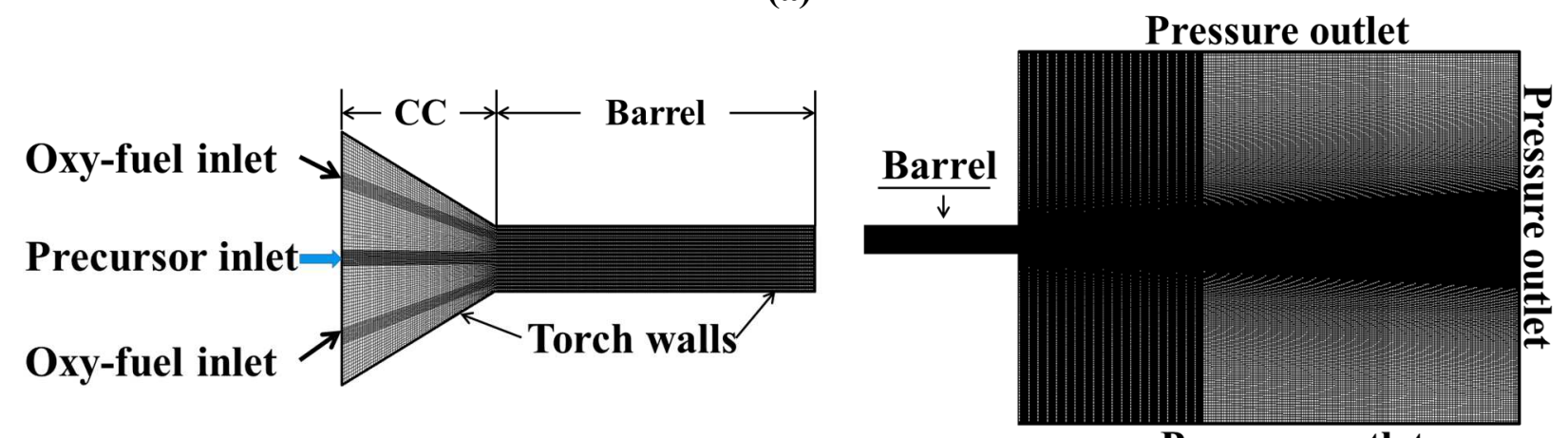

(b)

Pressure outlet

Figure 3. Axisymmetric, two-dimensional grids for (a) spray atomization in atmosphere for model validation (b) spray atomization in $\mathrm{CH}-2000 \mathrm{HVOF}$ torch application

The numerical modeling of the combustion process in the HVOF thermal spraying torch has been reported by many researchers ${ }^{37,44-47}$. The TAB modeled the secondary breakup of droplets $5,37,48-51$. For the supersonic combustion of propane inside the CH-2000 torch, a two-dimensional CFD-model 
is applied using the Eulerian continuum method. The droplet dynamics is captured by coupling of the Lagrangian model with the Eulerian continuum model. This coupling describes the multicomponent spray droplet breakup/atomization, transport, and evaporation in the computational domain. The eddy-dissipation model ${ }^{52-54}$ is used to express the reaction rate and to capture the interaction between eddy motion and chemical reaction. The applied mathematical models have been verified compared to experimental and numerical data ${ }^{33,37,44,45,55-59}$ and hence details are not repeated here for brevity.

\subsubsection{The modeling equations}

The modeling equations for the two-dimensional model in Cartesian tensor are presented here from $^{60,61}$ :

The equation for the conservation of mass:

$\frac{\partial \rho}{\partial t}+\frac{\partial}{\partial x_{i}}\left(\rho u_{i}\right)=0$

The equation for the conservation of momentum:

$\frac{\partial}{\partial t}\left(\rho u_{i}\right)+\frac{\partial}{\partial x_{j}}\left(\rho u_{i} u_{j}\right)=-\frac{\partial p}{\partial x_{i}}+\frac{\partial}{\partial x_{j}}\left(\tau_{i j}\right)_{e f f}+\frac{\partial}{\partial x_{j}}\left(-\overline{\rho u_{\imath} \dot{u}_{j}}\right)$

where the deviatoric stress tensor is given by

$\left(\tau_{i j}\right)_{e f f}=\mu_{e f f}\left(\frac{\partial u_{i}}{\partial x_{j}}+\frac{\partial u_{j}}{\partial x_{i}}-\frac{2}{3} \frac{\partial u_{i}}{\partial x_{i}} \delta_{i j}\right)$

The term $\left(\tau_{i j}\right)_{e f f}$ represents the viscous heating, and is always computed in the coupled solvers. It is enabled in the viscous model panel. The default value of the turbulent Prandtl number is 0.85 . Turbulent mass transfer is treated similarly, with a default turbulent Schmidt number of $0.7^{61}$.

In present work, the realizable $k-\varepsilon$ model is utilized for simulating turbulence in the HVOF torch, including compressibility effects ${ }^{60,62-64}$. The transport equations of realizable $k-\varepsilon$ model are given as in ${ }^{61,65,66}$ : 


$$
\begin{aligned}
& \frac{\partial}{\partial t}(\rho k)+\frac{\partial}{\partial x_{i}}\left(\rho k u_{j}\right)=\frac{\partial}{\partial x_{i}}\left[\left(\mu+\frac{\mu_{t}}{\sigma_{k}}\right) \frac{\partial k}{\partial x_{j}}\right]+P_{k}+P_{b}-\rho \varepsilon-Y_{M}+S_{k} \\
& \frac{\partial}{\partial t}(\rho \varepsilon)+\frac{\partial}{\partial x_{j}}\left(\rho \varepsilon u_{j}\right)=\frac{\partial}{\partial x_{j}}\left[\left(\mu+\frac{\mu_{t}}{\sigma_{\epsilon}}\right) \frac{\partial \varepsilon}{\partial x_{j}}\right]+\rho C_{1} S_{\varepsilon}-\rho C_{2} \frac{\varepsilon^{2}}{k+\sqrt{v \varepsilon}}+C_{1 \varepsilon} \frac{\varepsilon}{k} C_{3 \varepsilon} P_{b}+ \\
& S_{\varepsilon}
\end{aligned}
$$

In these equations, $P_{k}$ represents the generation of turbulence kinetic energy due to the mean velocity gradients, and $P_{b}$ is the generation of turbulence kinetic energy due to buoyancy. Flows with high-Mach-number, the compressibility affects turbulence through the dilatation dissipation; ignoring this would failed to predict the reduction in spreading rate with increasing Mach numbers for compressible mixing and other free shear layers. Here, $Y_{M}$ represents the contribution of the fluctuating dilatation in compressible turbulence to the overall dissipation rate. $C_{2}$ and $C_{1 \varepsilon}$ are constants; $\sigma_{k}$ and $\sigma_{\varepsilon}$ are the turbulent Prandtl numbers; and $S_{k}$ and $S_{\varepsilon}$ are user-defined source terms.

\subsubsection{Primary breakup model}

From Fluent the LISA model is applied to simulate the primary breakup of ligaments ${ }^{61}$. The dynamics of the liquid bubbles in the injector nozzle generates an air cavity enclosed by a liquid film. The thickness of this sheet $t$ is related to the mass flow-rate $\dot{m}_{e f f}$, nozzle exit diameter $D_{i n j}$, liquid density $\rho_{l}$ and axial velocity of liquid film $u=U \cos \theta$ by the following formula ${ }^{25,61}$.

$$
\dot{m}_{e f f}=\pi \rho_{l} u t\left(D_{i n j}-t\right)
$$

The total velocity of the liquid ejecting out from the nozzle section (U) is related to the injector pressure by 25,61

$$
U=k_{v} \sqrt{\frac{2 \Delta P}{\rho_{l}}}
$$

To make sure that the air cavity is nonnegative, the velocity coefficient $k_{v}$ is presented by ${ }^{25,61}$

$$
k_{v}=\max \left[0.7, \frac{4 \dot{m}_{e f f}}{d_{o}^{2} \rho_{l} \cos \theta} \sqrt{\frac{\rho_{l}}{2 \Delta P}}\right]
$$

where spray-angle $\theta$, and injection pressure $\Delta P$ are well-known. 
The LISA model analyzes the effects of pressurized gas and liquid properties on the fragmentation of the liquid film. Senecal et al. ${ }^{67}$ develop the details of the theoretical model whereas a very brief discussion is presented here. For a more robust implementation, the gas-phase velocity is neglected in calculating the relative liquid-gas velocity (here the gas-phase velocity means surrounding gas in which the spray is injected). This avoids having the injector parameters depend too heavily on the usually under-resolved gas-phase velocity field very near the injection location. The model assumes that a two-dimensional, viscous, incompressible liquid sheet of thickness $2 h$ moves with velocity $U$ through a quiescent, in viscid, incompressible gas medium. The liquid and the gas have densities of $\rho_{l}$ and $\rho_{g}$, respectively, and liquid viscosity is $\mu_{l}$. The infinitesimal wavy disturbance imposed on the initial steady motion has the form ${ }^{25,61,67}$ :

$$
\eta=\eta_{o} e^{-i k x+\omega t}
$$

where $\eta_{o}$ is the initial wave amplitude, $k=\frac{2 \pi}{\lambda}$ is the wave number, and $\omega=\omega_{r}+i \omega_{i}$ is the complex growth rate. The most unstable disturbance has the largest value of $\omega_{r}$, and is assumed to be responsible for sheet breakup. The most unstable disturbance can be calculated from the dispersion relation as a function of wave number $\omega=\omega(k)$ as derived in ${ }^{25,61,67}$.

The sheet breaks up and the ligaments formed with the length given by:

$$
L_{b}=\frac{U}{\Omega} \ln \left(\frac{\eta_{b}}{\eta_{o}}\right)
$$

where $\Omega$ is the maximum growth rate, and $\ln \left(\frac{\eta_{b}}{\eta_{o}}\right)$ is an empirical sheet constant. Dombrowski and Hooper ${ }^{68}$ showed that over a range of Weber number $\left(\mathrm{We}=\frac{\rho_{c} v_{r e l}^{2} d}{\sigma}\right)$ from 2-to-200, a value of 12 for the sheet constant is favorable compared with experimental sheet breakup lengths. The diameter of the ligaments formed at the point of breakup can be obtained from a mass balance. If it is assumed that the ligaments are formed from tears in the sheet twice per wavelength, the resulting diameter is given by ${ }^{25,61,67}$ : 


$$
d_{L}=\sqrt{\frac{8 h}{K_{S}}}
$$

Here, corresponding to the maximum growth rate $\Omega$, the wave number is $K_{s}$.

The breakup from ligaments to drops is assumed to behave according to Weber's analysis $25,61,67,69$ :

$$
d_{o}=1.88 d_{L}(1+30 h)^{1 / 6}
$$

Once $d_{o}$ is determined it is assumed that this droplet diameter is the most probable droplet size of a Rosin-Rammler distribution with a spread parameter of 3.5 and dispersion angle of $6^{\circ}$. Additional details of the model can be seen in ${ }^{25,61,67}$.

\subsubsection{Secondary breakup model}

The droplets secondary breakup is modeled by TAB model as We $<100^{48,50,61,70}$. By using the critical value of We, different regimes of the droplets disintegration are determined. The force required for the distortion of droplets is related to the surface-tension force acting to retain the droplet form by We. Since the Ohnesorge number $\left(\mathrm{Oh}=\frac{\mu}{\sqrt{\rho \sigma d}}\right)$ remains much below $0.1(\mathrm{Oh} \ll$ 0.1) in the domain, the key parameter related to breakup physics is the $\mathrm{We}{ }^{50,61,70}$. The Discrete Phase Model (DPM) treated the liquid droplets in Lagrangian manner and tracked the droplets throughout their flight. The TAB and DPM models validated in the earlier studies; details can be found in $5,25,48-50$.

\subsubsection{Droplets collision and coalescence model}

The collision model is most appropriate for low We collisions, where collision results in bouncing and coalescence. In the case of bouncing collision, the outcome is more oblique whereas, if the droplets collide head-on, then the outcome tends to be coalescence. The possibility of coalescence can be associated with the trajectory of the smaller droplet and the offset of collector droplet center. The distance between the center of one drop and the relative velocity vector is known as the critical offset $\left(b_{\text {crit }}\right)$. When surface energy dominates the phenomenon of coalescence take place, whereas 
bouncing occurs when kinetic energy dominates. The criterion, $b_{\text {crit }}$, determines the transition limit between various regimes: drops coalescence when $b \leq b_{\text {crit }}$, and bounces when $b>b_{\text {crit }}{ }^{8,13}$. The critical offset is a function of the collision $\mathrm{We}_{l}$ and the relative radii of the collector and smaller droplet. O’Rourke ${ }^{71}$ calculates the critical offset by using the following expression

$$
\begin{aligned}
& b_{\text {crit }}=\left(r_{1}+r_{2}\right) \sqrt{\min \left(1.0, \frac{2.4 f}{W e_{l}}\right)} \\
& \text { where } f \text { is a function of }\left(\frac{r_{1}}{r_{2}}\right) \text {, and is defined as } \\
& f\left(\frac{r_{1}}{r_{2}}\right)=\left(\frac{r_{1}}{r_{2}}\right)^{3}-2.4\left(\frac{r_{1}}{r_{2}}\right)^{2}+2.7\left(\frac{r_{1}}{r_{2}}\right)
\end{aligned}
$$

Here $r_{1}$ and $r_{2}$ are the radii of colliding larger and smaller droplets, respectively.

\section{RESULTS AND DISCUSSION}

\subsection{Model validation}

The graphs in Fig. $4^{37,42}$ illustrate the validation of the LISA model used in the present work. Here, the experimental work of Liu et al. ${ }^{7}$ and numerical work of Qian et al. ${ }^{15,20}$ are used for the validation. For validation, the spray of water droplet into the atmosphere with nozzle N3 was used. As explained earlier, the operating conditions are $\mathrm{P}_{\text {inj }}=0.6 \mathrm{Mpa}, \mathrm{D}_{\text {inj }}=0.4 \mathrm{~cm}, \mathrm{~m}_{\mathrm{w}}=1.6 \mathrm{~kg} / \mathrm{min}$ and the GLR is varied from $0.067,0.090,0.132,0.176$. Figure 4 illustrates that the numerical model can appropriately estimate the variations in spray droplets size (SMD) along the axial direction. For higher GLRs (0.132 and 0.176) the accuracy of the present numerical LISA model is better whereas this model shows some deviation along the axial direction (from 1-to-3 cm) for lower GLRs of 0.067 and 0.090 . 

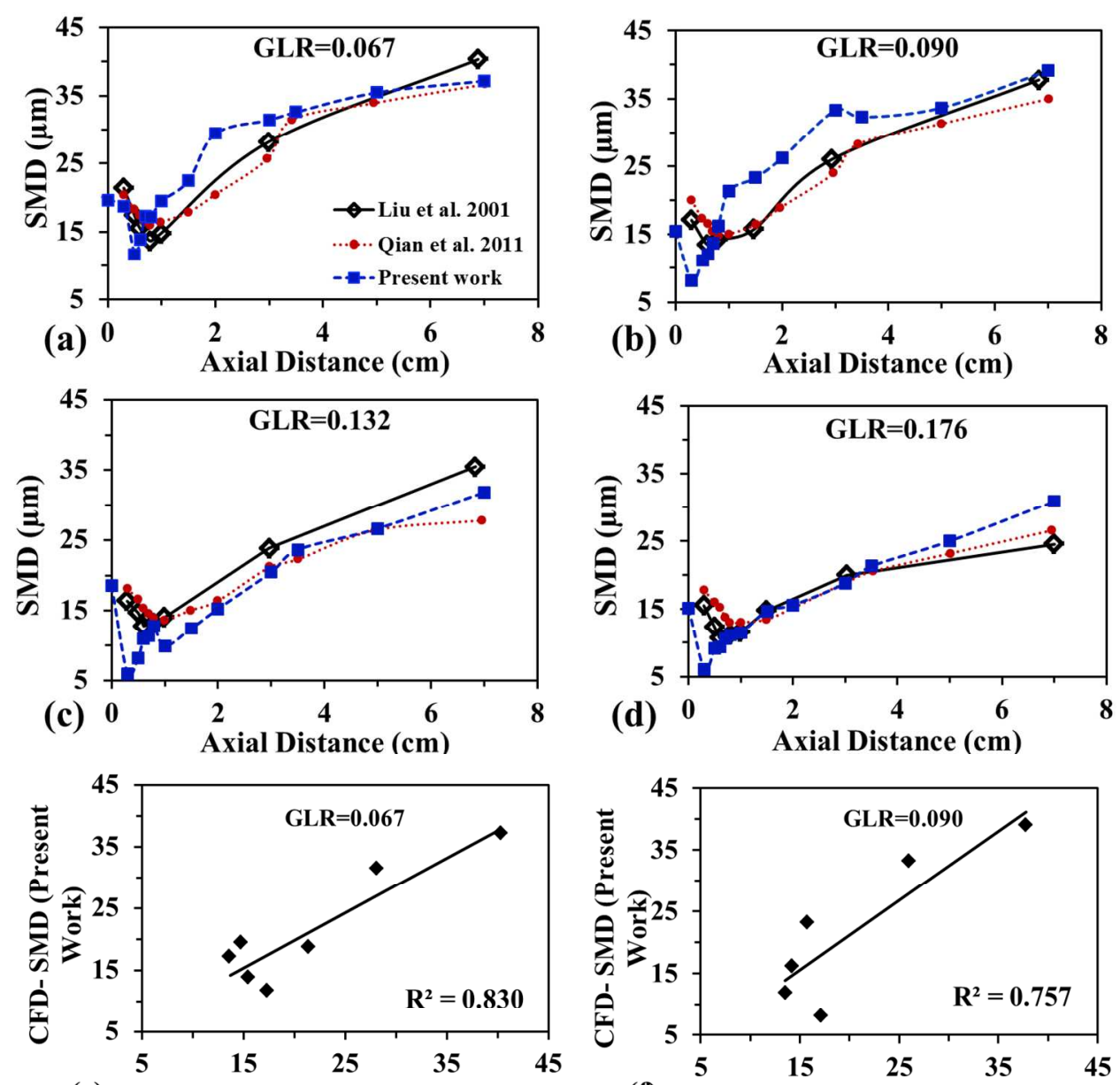

(e) Experimental SMD (Liu et al. 2001)

(f) Experimental SMD (Liu et al. 2001)
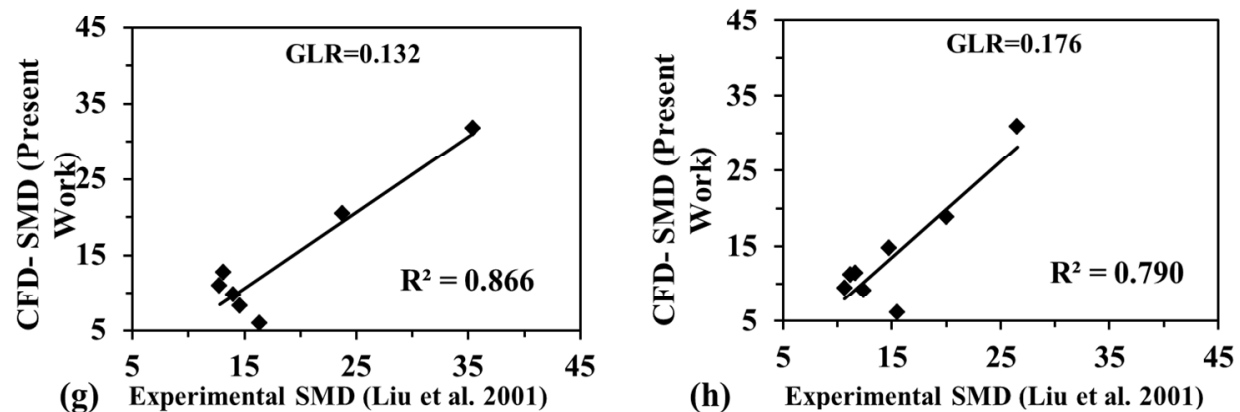

(h) Experimental SMD (Liu et al. 2001)

Figure 4. Graphical comparison of the present results with the work of Liu et al., $2001^{7}$ and Qian et al., $2011^{15,20}$ (a) GLR=0.067, (b) GLR=0.090, (c) GLR=0.132, (d) GLR=0.176 37,42 (e-f) The coefficients of determination $\left(\mathrm{R}^{2}\right)$ comparing CFD-SMD (present work) with experimental SMD values of Liu et al. ${ }^{7}$

Overall examination demonstrates that droplets diameter initially reduces and then increases along the axial direction ${ }^{7,8,15,20}$. The droplets reduction occurs due to high differences between relative velocities of atomization gas and droplets near the nozzle exit regions. However, the droplets with 
lower velocities collide with each other in the downstream regions, and the droplet diameter increases due to the coalescence ${ }^{15,20}$. Furthermore, it is analyzed that the increment in the GLR from $0.067-0.176$ decreases the size of droplets. This validation proves that LISA-model can predict the variations in droplets size in the spray by changing the injection parameters. Also, these results show good agreement with the experimental data. Hence, this model can be used in the numerical simulations of the effervescent spray atomization in the CH-2000 HVOF torch ${ }^{37,42}$. The coefficients of determination $\left(\mathrm{R}^{2}\right)$ is shown in Fig. $4 \mathrm{e}-4 \mathrm{~h}$, on scatter plot comparing CFD-simulation (present work) versus experimental values of Liu et al. ${ }^{7}$. As it is known that for ideal comparison regression line has a slope of one. Thus, in the present plots Fig. $4 \mathrm{e}-4 \mathrm{~h}$, the value of $\mathrm{R}^{2}$ is near to one for all cases it means that it does capture the variance of the respective data sets ${ }^{72}$.

\subsection{Comparison of Experimental and Numerical HVOF Flame Temperature}

The temperature sensing performed by thermocouples (as mentioned in section-2.3) is used to validate the numerical modeling using Ansys fluent CFD-code. For numerical validations of the gas flow dynamics, two cases are simulated Case1 and Case2, named with and without droplets injection. For Case1, the $\mathrm{O} / \mathrm{F}$ gases with nitrogen (as carrier gas) are injected into torch's CC; this case is named as CFD-without drops (see Fig. 5). Case2 is modeled for analyzing injection of puresolvents from the central hole having a constant diameter of $300 \mu \mathrm{m}$, using nozzle N3 with a feed rate of $50 \mathrm{ml} / \mathrm{min}$ (Table 1). In Case2, the flame temperature lowers down when $\mathrm{P}-\mathrm{W}$ and $\mathrm{W}-\mathrm{E}$ mixture solvents are used as injection solution. The flame temperature increases when P-E is injected into the $\mathrm{CC}$ as the heat is added due to combustion reaction caused by the evaporated ethanol droplets.

For all the cases the data are gathered and plotted here for combustion and droplets evaporation models validation (see Fig. 5). As stated in section-2.3 that the temperature sensing by thermocouple has significant errors and the deviation is about $\pm 200^{\circ} \mathrm{C}{ }^{43}$. Therefore, it is assumed 
that the actual flame temperature could be $200^{\circ} \mathrm{C}$ higher than the temperature measured by these thermocouples $30,31,37$.

Temperature profiles from numerical simulations of Case 1 and Case 2 are compared with the experimental measurements in Fig. 5. The temperature profiles measured by Realizable $k-\varepsilon$ CFDmodel in the far field are in good agreement with the experimental results in Case1 and Case2b. It can be said that droplets' evaporation is modeled perfectly by these simulations and it is evident by the decreasing flame temperature on the injection of $\mathrm{P}-\mathrm{W}$ and $\mathrm{W}-\mathrm{E}$ droplets injection; and the increment in temperature field that is observed for P-E injection case. Also, it is impossible to capture the fluid evaporation and temperature increment/or decrement inside the HVOF torch experimentally, thus only outer (free-jet) region has been considered and shown in Fig. 5 .

For numerical simulations of Case $2 \mathrm{a}$ and Case $2 \mathrm{c}, \mathrm{P}-\mathrm{W}$ and $\mathrm{W}-\mathrm{E}$ mixture droplets are fed into the CH-2000 torch and the CFD predictions of temperature are higher than the thermocouple measurements. The possible reason for disagreement has already been pointed out that the thermocouple could not measure the gas temperature accurately ${ }^{43}$. Hence, the flame temperature predicted by CFD is in the correct range as the measurements overlap completely with the hightemperature flame. On the other hand, for lower flame temperatures the CFD predictions are a little larger as compared with the thermocouples readings. Thus, it can be said that CFD predictions in Case $2 \mathrm{a}$ and Case $2 \mathrm{c}$ are more accurate, compared to the other cases.

When precursor droplets are injected into the torch, cooling of hot-gas effects is noticed. The variations in hot-gas temperature along the torch's centerline axis can be clearly seen in Fig. 5. It is observed from Fig 5 that by adding the liquid droplets in Case2, the flame temperature is significantly reduced. The highest peak flame temperature is detected in P-E Case $2 \mathrm{~b}(2828 \mathrm{~K}$, at $\mathrm{x}=$ $223 \mathrm{~mm})$, and the lowest peak flame temperature is perceived in P-W Case $2 \mathrm{a}(1677 \mathrm{~K})$. The maximum temperature observed for Case 1 is $2540 \mathrm{~K}$ and for Case $2 \mathrm{c}(\mathrm{W}-\mathrm{E})$, is $2500 \mathrm{~K}$. Therefore, 
for all prescribed cases the flame temperature is high enough to accomplish the in situ nanoparticles formation in the SPTS torch ${ }^{31,37}$.

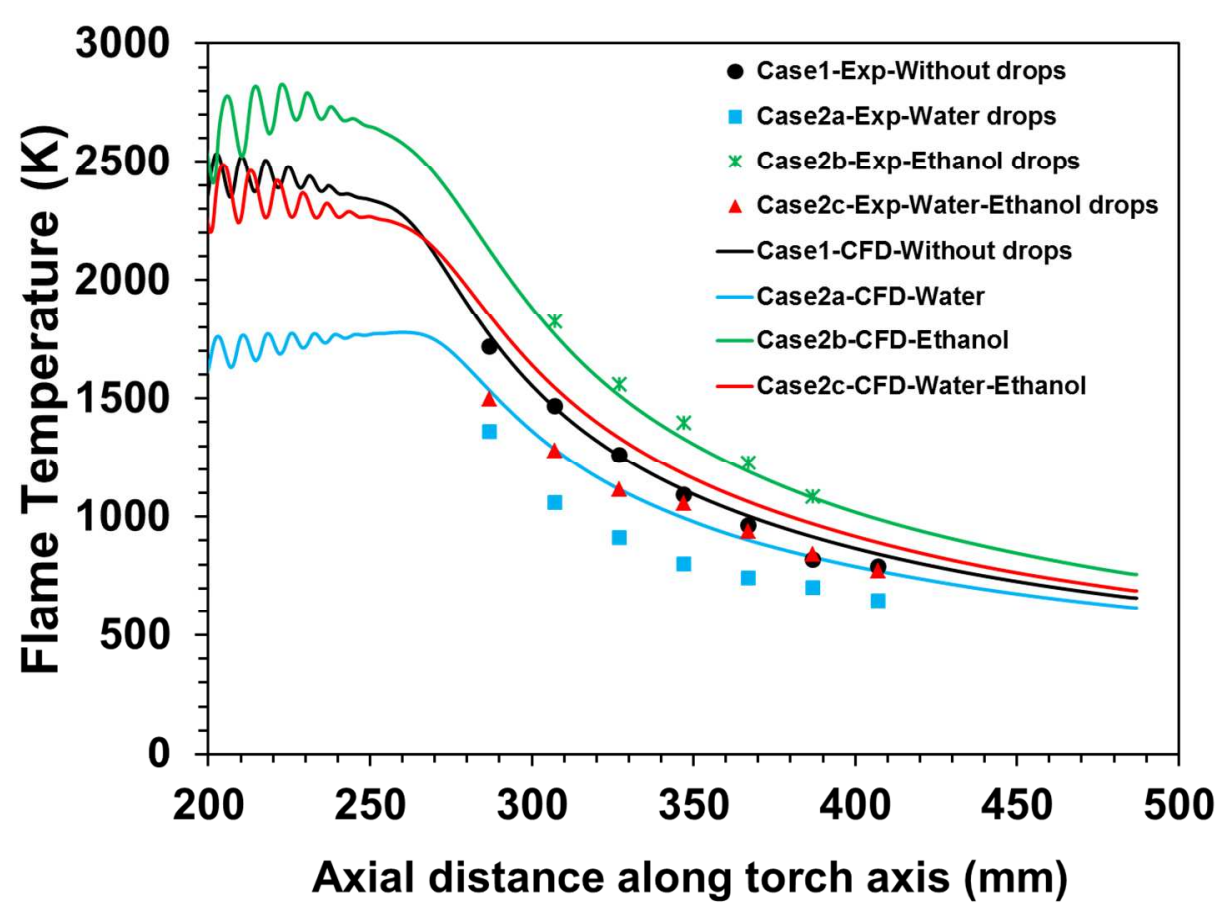

Figure 5. Thermocouple temperature measurements and CFD temperature predictions of the $\mathrm{CH}$ 2000 HVOF flame with injection of different solvent solutions (using nozzle N3)

\subsection{The effect of gas-to-liquid flow rate ratio on Sauter Mean Diameter}

In thermal spraying applications, it is desired that a small quantity of gas is introduced to achieve a proper atomization with small droplet size, as the higher GFR will cool the HVOF flame jet, and decreases its energy. The effervescent atomizer is used to be optimized by controlling the value_of GLR and it is observed that at lower GLR values it's operation efficiency increases ${ }^{19}$. Figure $6 \mathrm{a}$ illustrates the graphical comparison of SMD with varied liquid water and nitrogen GFRs. The nozzle exit diameter is $1.5 \mathrm{~mm}$, and the operating-pressure is set at $0.7 \mathrm{Mpa}$, while the gas and liquid flow rates (LFRs) are changed. As mentioned in the figure caption, Fig. 6a has a constant GFR ( $\left.Q_{\text {gas }}\right)$ of 8 1/min while LFR (QP-W) is varied; different values are 50, 100 and $200 \mathrm{ml} / \mathrm{min}$. The increase in the SMD is observed by an increment in the water injection flow rate [from 50 to 100 $\mathrm{ml} / \mathrm{min}$, and from 100 to $200 \mathrm{ml} / \mathrm{min}$ ] and larger size droplets are observed for lower GLR values ${ }^{6}$. 
The reason is that less quantity of gas is supplied to disintegrate a significant amount of liquid; therefore, less energy is transferred to the liquid which generates bigger diameter droplets. Figure 6a also demonstrates that this kind of effervescent atomizer is capable of producing a spray with the initial droplet size of less than $20 \mu \mathrm{m}$ up to a spray distance of $3 \mathrm{~cm}$. Also, the droplet size remains well below $50 \mu \mathrm{m}$ till it reaches a spray distance of $10 \mathrm{~cm}$ from the nozzle exit. Hence, the spray nozzle is capable of producing high atomization energy that keeps the size of droplets below $50 \mu \mathrm{m}$.

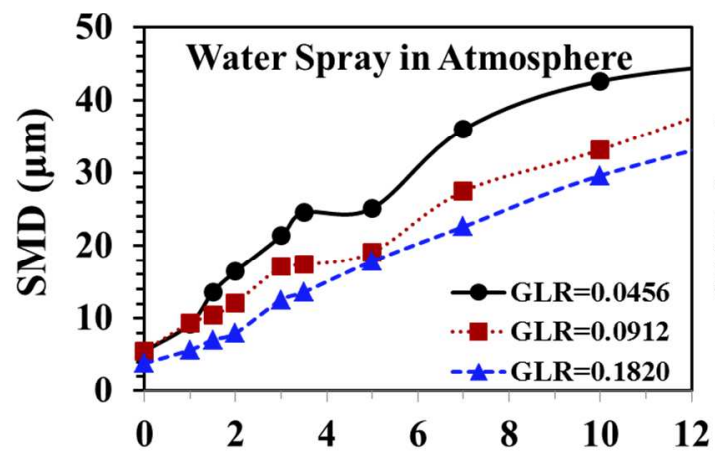

(a) Axial distance (cm)

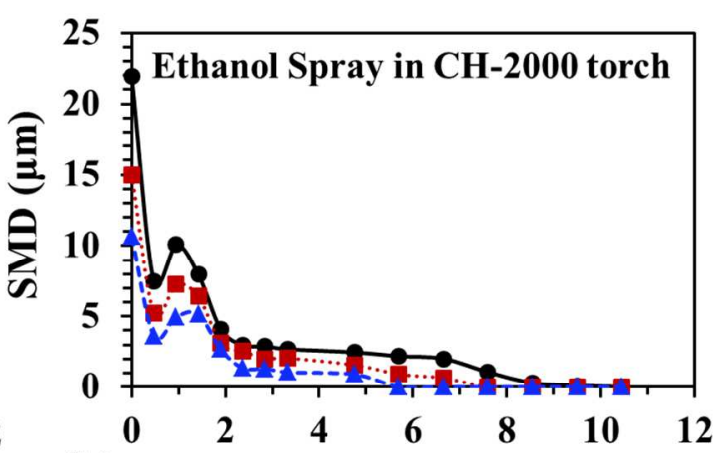

(b) Axial distance (cm)

Figure 6. Comparison of $\mathrm{SMD}$ at varying GLR with $\mathrm{Q}_{\mathrm{gas}}=8$ 1/min, $\mathrm{Q}_{\text {liquid }}=200 \mathrm{ml} / \mathrm{min}(\bullet-), 100$ $\mathrm{ml} / \mathrm{min}(-)$, and $50 \mathrm{ml} / \mathrm{min}(-)$ for (a) Water spray in atmosphere and (b) Ethanol spray in $\mathrm{CH}$ 2000 torch

When this effervescent atomization nozzle is used for the injection of P-E in the CH-2000 HVOF torch, the SMD has been enormously reduced (Fig. 6b). As the HVOF combustion flames have a higher amount of kinetic energy, it supports the droplets disintegration inside the HVOF torch ${ }^{5,73}$. Moreover, in the flame jet, P-E droplets are evaporated and the droplets completely converted into the ethanol vapors which then burn inside the torch and improve its thermal and kinetic energies ${ }^{42}$. However, the increment in the P-E's LFR $\left(\mathrm{Q}_{\mathrm{P}-\mathrm{E}}\right)$ has an adverse effect on the droplet breakup, and at higher LFR the reduction in SMD is smaller as compared to lower LFR (Fig. 6b). Nevertheless, the droplets size remains well below $25 \mu \mathrm{m}$ even for the higher LFR. Thus, it substantiates that this type of atomizer can work well for precursor injection in the HVOF torches for the production of nanosize particles that eventually lead to the generation of dense coatings. 


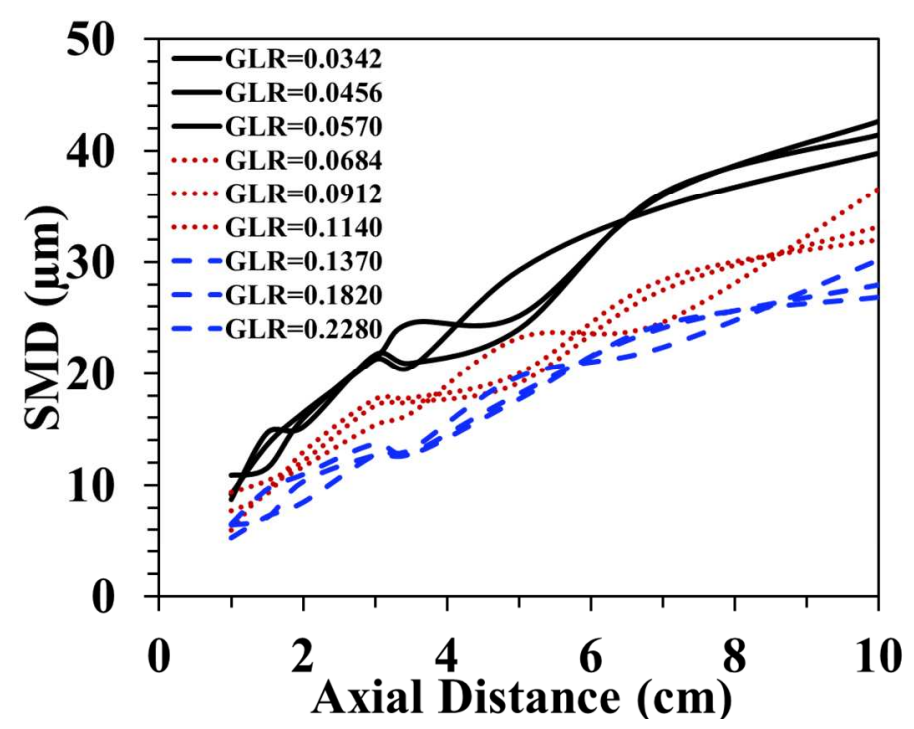

Figure 7. Variations in SMD with different GLR along axial direction in the atmospheric spray [The blue dashed lines are for the $\mathrm{LFR}=50 \mathrm{ml} / \mathrm{min}$, the red dotted lines $\mathrm{LFR}=100 \mathrm{ml} / \mathrm{min}$, and the solid black lines for the $\mathrm{LFR}=200 \mathrm{ml} / \mathrm{min}$ ]

Different cases are simulated for the P-W spray into the atmosphere with varied GLR. It is observed that when the GFR is increased while keeping LFR constant, a small effect on SMD is detected (Fig. 7). The blue dashed lines are for the smallest LFR of $50 \mathrm{ml} / \mathrm{min}$, and the droplet size remains below $30 \mu \mathrm{m}(\mathrm{d}<30 \mu \mathrm{m})$ throughout the spray region. For $100 \mathrm{ml} / \mathrm{min} \mathrm{LFR}$, the largest droplet sizes are in the range of 30-38 $\mu \mathrm{m}$ (red dotted lines in Fig. 7). The solid black lines are for the LFR of $200 \mathrm{ml} / \mathrm{min}$ and the droplet size increases up to $40-42 \mu \mathrm{m}$ when the GFR changes from 10-6 1/min. The bigger droplet diameters are detected for higher LFR when compared to lower LFR throughout the axial distance of spray region from 1-10 cm. Hence, the smallest values of SMD are observed when the lowest value of LFR $(50 \mathrm{ml} / \mathrm{min})$ is used, and it improves the droplets' breakup efficiency of the effervescent type nozzle. Thus, it is evident that higher GLR increases the droplet disintegration or the droplets breakup efficiency. However, the overall atomization efficiency is decreased. The cause of this deficiency is that a disproportionate amount of energy is needed to form finer spray with smaller size droplets, as the energy losses due to friction, turbulence, and acceleration increase ${ }^{74,75}$. 


\subsection{The effect of nozzle exit diameters on Sauter mean diameter}

Lefebvre et al. ${ }^{11}$ found that by using a small diameter orifice the smallest droplet size can only be produced with lowest GLR and low operating pressures. While for GLR $>0.08$ and pressure $\mathrm{P}_{\text {inj }}>138$ $\mathrm{kPa}$ they concluded that atomization is insensitive to the diameter of the discharge orifice ${ }^{11,76}$. Moreover, it is understood that the advantage of using a bigger diameter orifice can eliminate the problems of contamination. In the present work some cases are simulated with a constant value of $P_{\text {inj }}=0.7 \mathrm{Mpa}$ and GLR $=0.182$, and varied injector orifice diameters of $\mathrm{D}_{\text {inj }}=0.5,1.0$ and $1.5 \mathrm{~mm}$, to analyze the effect over spray atomization. Figure 8a illustrate that nozzle exit diameter has some impact on the SMD in the far field region of spray at $\mathrm{x}>3 \mathrm{~cm}$ while no significant difference is observed in the near-nozzle exit region. Moreover, the lowest droplet size is observed for the biggest nozzle exit diameter of $D_{\text {inj }}=1.5 \mathrm{~mm}$ while larger droplet sizes are seen for the smallest diameter orifice of $D_{i n j}=1.0 \mathrm{~mm}$. The reason could be the insensitiveness of the model on $D_{\text {inj }}$ as the dependence of SMD is more visible when the values of model inputs such as spray-half-angle, liquid sheet constant, and atomizer dispersion angle are varied. In the present LISA model, all injection parameters remain constant, and only $\mathrm{D}_{\mathrm{inj}}$ is varied, and it is one of the reasons that insignificant effects over the SMD are observed.

The increase in the effervescent nozzle exit diameter has minor effects over the SMD when P-E is sprayed in the CH-2000 torch (Fig. 8b). Near the nozzle exit region, it is observed that the initial droplets size observed for the smallest $D_{\text {inj }}=0.5 \mathrm{~mm}$ is $d_{i}=18 \mu \mathrm{m}$ compared to $d_{i}=11 \mu \mathrm{m}$ and $12 \mu \mathrm{m}$ for $\mathrm{D}_{\mathrm{inj}}=1.5 \mathrm{~mm}$ and $2.0 \mathrm{~mm}$, respectively. However, the droplet fragmentation is greater for $\mathrm{D}_{\mathrm{inj}}=0.5 \mathrm{~mm}$ compared to that of $\mathrm{D}_{\mathrm{inj}}=1.5 \mathrm{~mm}$ and $2.0 \mathrm{~mm}$. Overall, it is observed that the effervescent nozzle works efficiently even with the bigger $\mathrm{D}_{\mathrm{inj}}$. Thus, this type of injection nozzle can be beneficially used in the suspension and solution precursor thermal spraying with minimized clogging. 


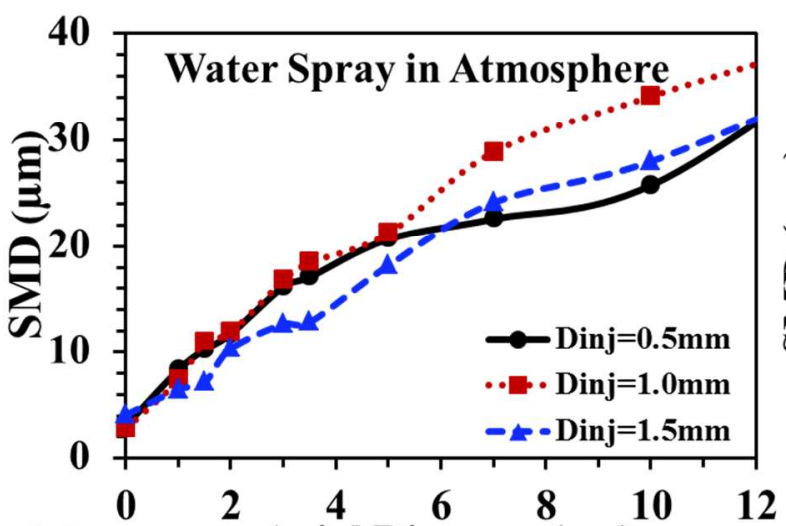

(a) Axial Distance (cm)

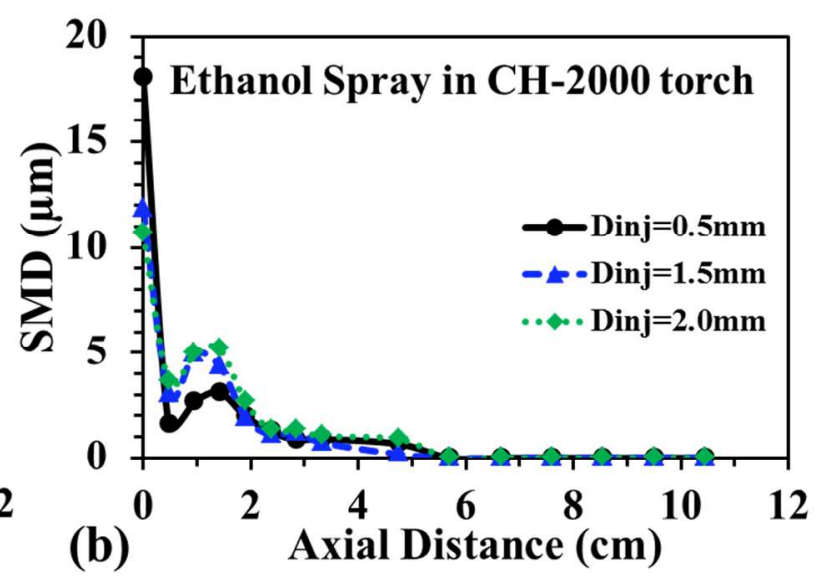

Figure 8. Comparison of $\mathrm{SMD}$ at constant $\mathrm{GLR}=0.182$ and $\mathrm{P}_{\mathrm{in}}=0.7 \mathrm{Mpa}$ with various nozzle exit diameters $\left(D_{\text {inj }}\right)$ at different operating pressures (a) Water spray in atmosphere and (b) Ethanol spray in $\mathrm{CH}-2000$ torch

\subsection{The effect of solvent type on Sauter mean diameter}

The effervescent atomizer is tested to atomize various liquids, including P-W, P-E and W-E mixture with different viscosities and surface-tensions. The properties of these liquids are provided in Table 2. It is stated in ${ }^{8,22}$ that effervescent atomizer can work efficiently even with highly viscous fluids and liquid viscosity has small effects on droplet size and distribution. Also, finer droplet atomization can be achieved by using lower liquid density and surface-tension solvents. Moreover, the We play a significant role in the analysis of droplet disintegration phenomena ${ }^{20,21}$. The definitions of the We $\left(=\frac{\rho_{\mathrm{c}} \mathrm{v}_{\text {rel }}^{2} \mathrm{~d}}{\sigma}\right)$ and the $\mathrm{Oh}\left(=\frac{\mu}{\sqrt{\rho \sigma \mathrm{d}}}\right)$ contain the thermophysical properties of fluid like density $\rho$, surface-tension $\sigma$, and droplet viscosity $\mu$, and hence, the atomization phenomenon can easily be studied by the droplet Weber and Ohnesorge number ${ }^{20,21}$. Figure $9 \mathrm{a}$ shows the comparison of the We for two different liquids P-W and P-E spray in the atmosphere. It can be seen that P-E has the higher values of We in comparison to P-W. It can be estimated from the property data displayed in Table 2 that the value of the surface-tension of P-W $\left(\sigma_{\mathrm{P}-\mathrm{W}}=71.94 \times 10^{-3}\right.$ $\mathrm{N} / \mathrm{m})$ is three times that of P-E $\left(\sigma_{\mathrm{P}-\mathrm{E}}=22.348 \times 10^{-3} \mathrm{~N} / \mathrm{m}\right)$. Therefore, higher surface-tension 
suppresses fragmentation and higher gas kinetic energies are required to disintegrate the P-W droplet, as compared to the P-E droplet. Furthermore, the value of We is greater in the near-nozzle exit regions for both fluids. It decreases gradually along the length of spray, and then in the far field regions of spray $(x>10 \mathrm{~cm})$, the value of We again increases. Hence, the main fragmentation is occurring in near exit regions and far field regions of an effervescent spray into the atmosphere (Fig. 9a).

Table 2. The thermophysical properties of liquids

\begin{tabular}{lccc}
\hline \hline Solvent & Density $\left(\mathrm{kg} / \mathrm{m}^{3}\right)$ & Viscosity $(\mathrm{kg} / \mathrm{m}-\mathrm{s})$ & Surface-tension $(\mathrm{N} / \mathrm{m})$ \\
\hline \hline Pure Water (P-W) & 998.2 & 0.001003 & 0.0719404 \\
Pure Ethanol (P-E) & 790 & 0.00120 & 0.022348 \\
Water-Ethanol (W-E) & 894 & 0.00110 & 0.047144 \\
\hline
\end{tabular}

In analyzing the effects of varied liquid properties on the effervescent atomization in the $\mathrm{CH}-2000$ torch, different simulations are performed based on Table 2 data. The results are shown in Fig. 9b-c that demonstrates the variations in the droplet diameter for liquids with different thermophysical properties. It is determined that droplet diameter is increased by an increment in the liquid density, viscosity, and surface-tension. The initial values of SMD at $x=0 \mathrm{~cm}$ is highest for $\mathrm{P}-\mathrm{W}$ case $(19 \mu \mathrm{m})$ and lowest for P-E case $(11 \mu \mathrm{m})$. It is according to previous findings that the droplet size increases with increment in the surface-tension of liquids ${ }^{15}$. Here, the P-W has the maximum surface-tension of $0.071904 \mathrm{~N} / \mathrm{m}$ and higher values of SMD in the near-nozzle exit regions (from $x=0-10 \mathrm{~cm}$ ) are observed. Moreover, for P-W and W-E mixture cases, the droplet size is further increased in the axial distance due to coalescence. The P-E droplets observed a reduction in diameter with slight coalescence occurred in the midsection of torch $\mathrm{CC}$, and then they evaporated completely at $x=5.8$ $\mathrm{cm}$ in the barrel section. Finally, it is predicted that even with high surface-tension liquids, such as P-W, the droplet SMD remains below $20 \mu \mathrm{m}$; and thus this type of nozzle can efficiently work as a good atomizer. 


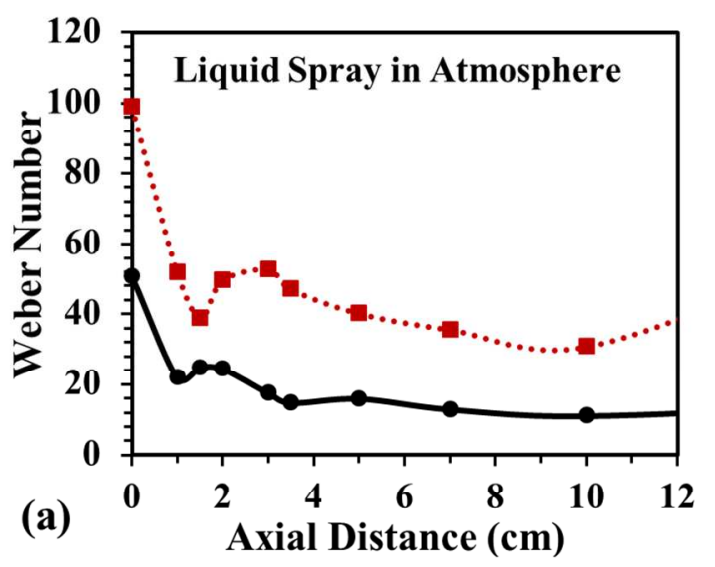

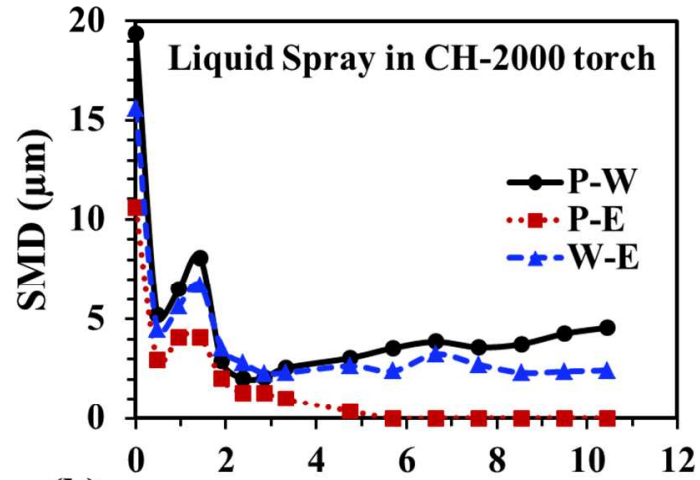

(b) Axial Distance (cm)

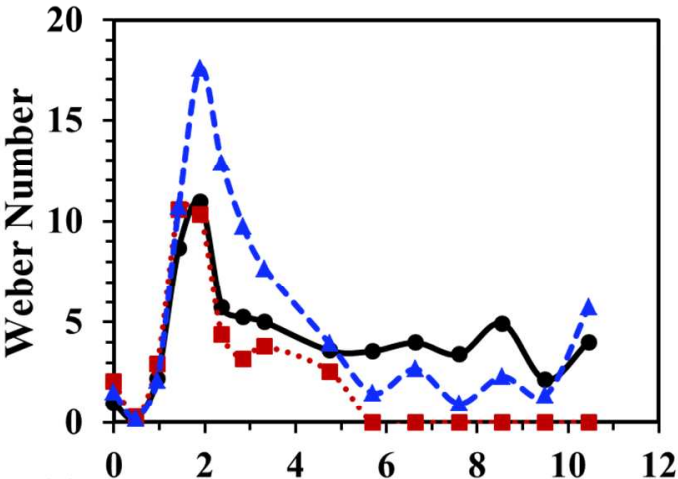

(c) Axial Distance (cm)

Figure 9. Comparison of Weber number and SMD, at constant $P_{\text {inj }}=0.7 \mathrm{Mpa}, \mathrm{GLR}=0.182$, and $\mathrm{D}_{\mathrm{inj}}=1.5 \mathrm{~mm}$, for different solvents sprayed in (a) atmosphere, (b, c) CH-2000 torch

Comparison of values of We for droplets in the computational domain is depicted in Fig. 9c. In the case of W-E, the We reached a peak value of about 18 near the exit of CC; whereas, the primary atomization occurs due to relative velocities between the droplets and the gas phase in the CC. However, the value of We remains below 12 for P-W and P-E cases. As mentioned above that the value of the surface-tension of $\mathrm{P}-\mathrm{W}$ is three times of $\mathrm{P}-\mathrm{E}$; thus, in the $\mathrm{CH}-2000$ torch, the increment in surface-tension also deteriorates the precursor's droplets fragmentation (Table 2). Overall, it can be said that this type of nozzle N3 can perform well as no significant effect on SMD is observed and it remains below $20 \mu \mathrm{m}$ even with higher values of surface-tension, viscosities, and densities ${ }^{15,22}$. 


\subsection{The effect of injection nozzle type on Sauter mean diameter}

The three different types of injection nozzle are tested numerically to observe the effects over the droplets disintegration (Fig. 2). In the present work the plain-orifice (N1) and angular injection (N2), nozzles use only single fluid solution precursor without any atomizing gas. The N1 injected the liquid into the $\mathrm{CC}$ of the $\mathrm{CH}-2000 \mathrm{HVOF}$ torch at an angle of injection of $\alpha=0^{\circ}$ (Fig. 2), and all the droplets traveled along the torch's central axis (Fig. 10a). As stated earlier that the nozzle N1 exit diameter is $0.5 \mathrm{~mm}$ and the initial diameter of droplets ejecting out from the nozzle is $\mathrm{d}_{\mathrm{i}) \mathrm{N} 1}=500$ $\mu \mathrm{m}$. The droplet breakup starts inside the $\mathrm{CH}-2000 \mathrm{HVOF}$ torch due to the velocity differences between the injected droplets and combustion gas. These high relative velocities exert an aerodynamic force onto the injected droplets. Thus, the droplet breakup started and continued. A comparison for the reduction of SMD is shown in Fig. 10b for varied nozzles types of N1, N2, and N3. The result of N1 shows the secondary breakup and a reduction in the diameter of $500 \mu \mathrm{m}$ droplets; it is observed that droplets experience a sharp decline in diameter from $500 \mu \mathrm{m}-125 \mu \mathrm{m}$, and $125 \mu \mathrm{m}-35 \mu \mathrm{m}$ in the torch's CC. At $\mathrm{x}=4.75 \mathrm{~cm}$, the droplets disappeared due to complete evaporation in the barrel section.

In angular injection, the P-E is fed into the CC of the HVOF torch at an angle of $\alpha=60^{\circ}$ (Fig. 10a). It is analyzed that the initial droplet size is equal to the nozzle exit diameter $(300 \mu \mathrm{m})$. In the case of nozzle $\mathrm{N} 2$, the $60^{\circ}$ angle of injection is very high, and it causes the droplets to collide with the torch's CC walls and then converges back to the axis of the torch as seen in Fig. 10a. As the size of exit orifice diameter is smaller $\left(\mathrm{d}_{\mathrm{i}) \mathrm{N} 2}=300 \mu \mathrm{m}\right)$, the tendency for droplet size reduction enhances during N2 injection. Thus, due to the reduced injection diameter, N2 shows a faster reduction in droplet diameter as compared to N1. For N2, the sharp decrease in the droplet's diameter is also detected in the $\mathrm{CC}$ of the $\mathrm{CH}-2000$ torch from $300 \mu \mathrm{m}-75 \mu \mathrm{m}$ and then from $75 \mu \mathrm{m}-25 \mu \mathrm{m}$. At $\mathrm{x}=10.5 \mathrm{~cm}$, the droplet diameter is reduced to $1 \mu \mathrm{m}$ and are completely evaporated at $\mathrm{x}=15 \mathrm{~cm}$. 


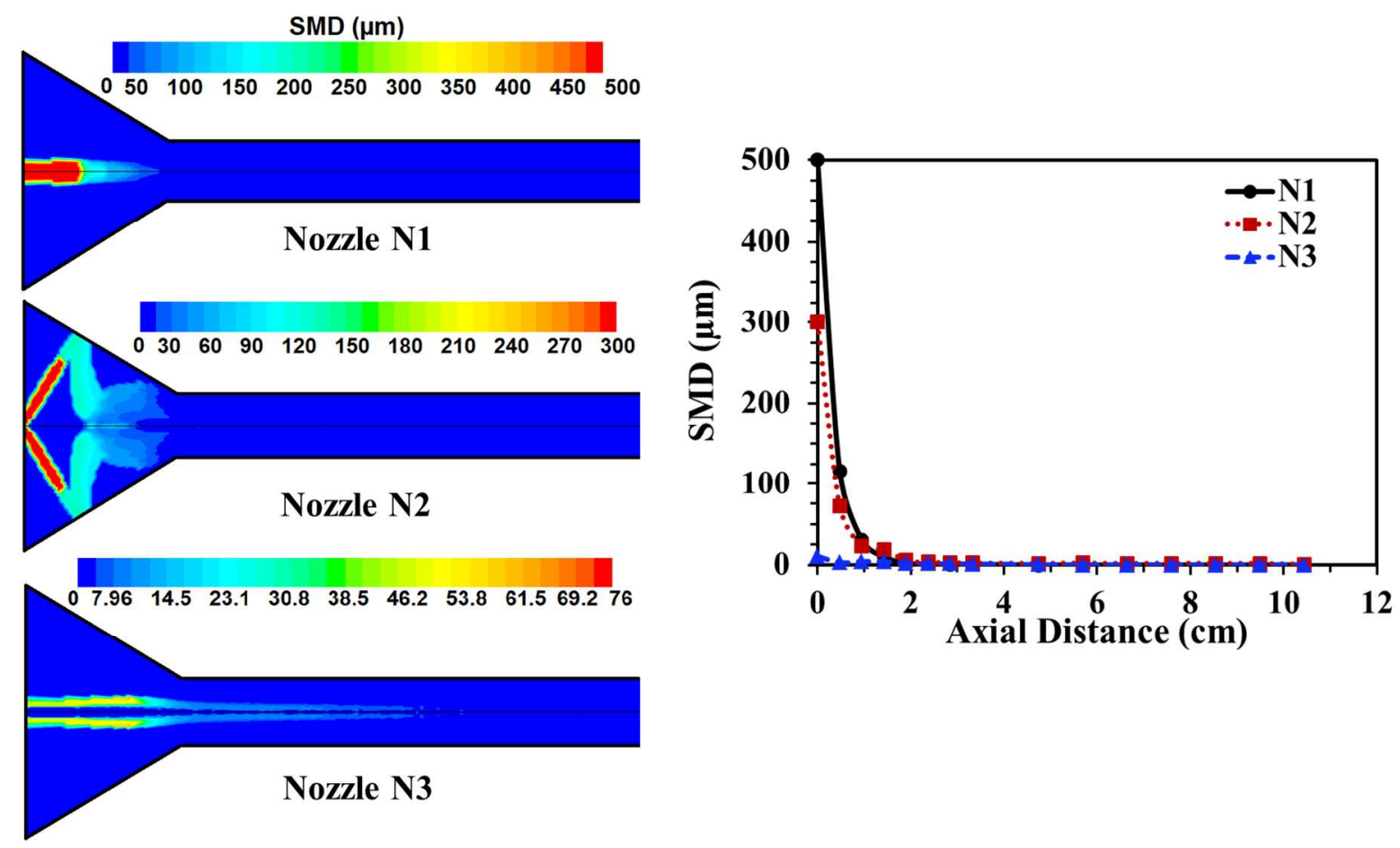

(10)

(b)

Figure 10. Comparison of SMD using P-E solvent injected at constant Pinj=0.7 Mpa, GLR=0.182, and with varied nozzle types (a) Contours plot, and (b) graphical representation

The new effervescent atomization technique is applied to disintegrate the precursor droplets to smaller size $<20 \mu \mathrm{m}$ that resulted in the formation of nanoparticles' size $<100 \mathrm{~nm}$ with improved morphology ${ }^{31}$. The nozzle N3 uses the twin-fluid flow through a nozzle and at the point of ejection the gas core is confined by a liquid layer; hence, because of the pressure differences between the two fluids (gas and liquid), the liquid sheet is shattered by the high-pressure gases (Fig. 10a). This causes disintegration of the liquid feedstock ${ }^{6,8}$. In the case of nozzle $\mathrm{N} 3$, due to the atomization of the precursor droplets, the smaller size droplets of $\mathrm{d}=11 \mu \mathrm{m}$ are formed at the point of initial injection $\mathrm{x}=0 \mathrm{~cm}$ (Fig. 9b-case P-E, Fig. 10b). These droplets further fragmented into $\mathrm{d}=3 \mu \mathrm{m}$ inside the CH-2000 torch's CC. Small coalescence is observed in the middle of CC, and the droplet size becomes $\mathrm{d}=4 \mu \mathrm{m}$, however, due to higher relatives velocities, these droplets shattered into the smaller size and are evaporated completely in the barrel section at $\mathrm{x}=5.7 \mathrm{~cm}$. 
Overall, the best performance is observed for nozzle N3 compared to all other injection types (Fig. 10a-b). The effervescent atomization can improve the droplets' fragmentation that led to the complete evaporation of the solution or suspension carrying the nanoparticles. Thus, the in-situ heating process of the reduced sized solution or suspension droplets can result in the formation of smaller size nanoparticles with the improved morphology. Moreover, the thermophysical properties of the liquid solution or suspension have no significant effects on the performance of the effervescent atomizer, and even with the higher density, viscosity or surface-tension the mean droplets size remains well below $20 \mu \mathrm{m}$ (Fig. 9).

\section{CONCLUSIONS}

In present work, LISA model from Fluent is utilized to investigate the liquid feedstock atomization effects over the gas and droplets dynamics. The modeling of the new effervescent atomization made the investigation process easier. The CFD-modeling analyses provided in this paper are a cheap tool which eases to study the use of different atomizing nozzle types in various HVOF torch designs. The setup of computational modeling can also be utilized for different kinds and designs of HVOF torch using different combustion fuels and liquid feedstock. Moreover, atomization modeling can be used for various injection nozzles designs. It will reduce the burden of expensive experimental lab testing. Hence, it is an enormous piece of modeling work that can positively benefit the thermal spraying industry. Here, the phenomenon of effervescent atomization is analyzed numerically for solution precursor droplets disintegration in the HVOF torch. The droplet size distribution is measured for different GLR, $\mathrm{D}_{\mathrm{inj}}$, and $\mathrm{P}_{\mathrm{inj}}$, various types of solvent and injection nozzles. CFD-modeling is performed and validated by the previous work. Different injection parameters are numerically tested, and results are compared to observe the effects on droplet disintegration phenomenon. Furthermore, the impact of liquid properties on droplet fragmentation is analyzed by using various liquids P-W, P-E and W-E mixture. Finally, the 
effervescent type injection nozzle is compared with other injection nozzle types. Following conclusions are drawn from the current work:

- The CFD-modeling of the HVOF flame temperature is in good agreement with the experimentally measured temperature in the free jet section of the flame. The temperature in the SPTS torch is high enough to support the solution precursor droplets evaporation and nanoparticles' in situ formation.

- The LISA model can predict variations in spray atomization with respect to changing injection parameters and is in good agreement with the experimental results.

- In overall comparison, it is analyzed that the droplets size is significantly varied with the external spray conditions. The spray in the atmosphere has droplet size ranged from $10 \mu \mathrm{m}-44$ $\mu \mathrm{m}$, and due to the droplet's coalescence SMD increased in the axial direction. Whereas, in the case of spray in the $\mathrm{CH}-2000 \mathrm{HVOF}$ torch, the droplet size reduced from $20 \mu \mathrm{m}-3 \mu \mathrm{m}$, and coalescence is insignificant. The reason is the evaporation of the droplets in the hightemperature zones of the HVOF torch.

- Effervescent atomization is significantly dependent on GLR variations. An increase in the GLR will increase the droplets' fragmentation efficiency of the atomizer hence generate smaller size droplets. However, high GLR and high gas input pressure resulted in higher energy consumption; therefore optimization is required for the best overall operation. The present effervescent nozzle design works efficiently with GLR 0.034-0.228.

- Moreover, the effects of nozzle exit diameter and injection pressure observed by the LISA model are not very significant. The reason could be the use of constant input values of sprayhalf-angle, liquid sheet constant, and atomizer dispersion angle.

- For the spray in the atmosphere, the Weber number demonstrates that liquids having higher surface-tension require more energy to disintegrate the droplets at the first point as compared to 
lower surface-tension fluids. The effect of various liquid properties, such as density, viscosity, and surface-tension has no significant impact on the performance of the effervescent atomization inside the $\mathrm{CH}-2000$ torch and the droplet size remains below $20 \mu \mathrm{m}$ even for P-W case.

- After the comparison of varied nozzles types, it is concluded that the effervescent nozzle is the best choice for the proper disintegration of the solution precursor inside the HVOF torch.

\section{ACKNOWLEDGEMENTS}

The author would like to acknowledge the financial support from the NED University of Engineering \& Technology Pakistan, and the UK Engineering and Physical Sciences Research Council (EPSRC) project grant: EP/K027530/1. The injection nozzle designing performed in the Xian Jiaotong University, China is guided by Prof. Chang-Jiu Li and Dr. Shan-Lin Zhang. This work is funded by "European Seventh Framework program-Marie Curie Actions-People International Research Staff Exchange Scheme” under project grant-268696.

$\begin{array}{ll}\text { ABBREVIATIONS } \\ \text { CC } & \text { Combustion Chamber } \\ \text { CFD } & \text { Computational Fluid Dynamics } \\ \text { GFR } & \text { Gas Flow Rate } \\ \text { GLR } & \text { Gas-to-Liquid flow rate Ratio } \\ \text { HVOF } & \text { High-Velocity Oxygen Fuel } \\ \text { LFR } & \text { Liquid Flow Rate } \\ \text { LISA } & \text { Linear Instability Sheet Atomization } \\ \text { O/F } & \text { Oxygen-fuel } \\ \text { SPTS } & \text { Solution Precursor Thermal Spraying } \\ \text { SPS } & \text { Suspension Plasma Spraying } \\ \text { TAB } & \text { Taylor Analogy Breakup }\end{array}$




\section{NOMENCLATURE}

\section{Symbols}

$d_{o}=$ Volume median diameter (m)

$d=$ Droplets' diameter $(\mu \mathrm{m})$

$d_{L}=$ Diameter of ligament $(\mathrm{m})$

$D_{i n j}=$ Nozzle exit diameter $(\mathrm{m})$

$2 h=$ Liquid sheet thickness $(\mathrm{m})$

$k=$ wave number

$k_{v}=$ Velocity coefficient

$L_{b}=$ Ligaments length (m)

$\dot{m}_{\text {eff }}=$ Mass flow rate $(\mathrm{kg} / \mathrm{s})$

$n=$ Spread Parameter

$\Delta P=$ injection pressure $(\mathrm{MPa})$

$\mathrm{Oh}=\frac{\mu}{\sqrt{\rho_{d} \sigma d}}=$ Ohnesorge number $(\mathrm{Oh})$

$t=$ Thickness of liquid film (m)

$u=$ Axial velocity of liquid film $(\mathrm{m} / \mathrm{s})$

$U=$ Total velocity $(\mathrm{m} / \mathrm{s})$

$v_{\text {rel }}=$ Relative velocity of droplets $(\mathrm{m} / \mathrm{s})$

$\mathrm{We}=\frac{\rho_{d} v_{r e l}^{2} d}{\sigma}=$ Weber number $(\mathrm{We})$

\section{Greek symbols}

$\mu=$ Droplets' viscosity $(\mathrm{kg} / \mathrm{m} \bullet \mathrm{s})$

$\rho_{d}=$ Droplets' density $\left(\mathrm{kg} / \mathrm{m}^{3}\right)$

$\rho_{c}=$ Combustion gas density $\left(\mathrm{kg} / \mathrm{m}^{3}\right)$

$\rho_{l}=$ Liquid density $\left(\mathrm{kg} / \mathrm{m}^{3}\right)$

$\rho_{g}=$ Atomization gas density $\left(\mathrm{kg} / \mathrm{m}^{3}\right)$

$\eta_{o}=$ Initial wave amplitude

$\eta=$ Infinitesimal wavy disturbance

$\sigma=$ Droplets' surface-tension $(\mathrm{N} / \mathrm{m})$

$\theta=$ Spray half angle

$\omega=$ Complex growth rate

$\alpha=$ Angle of injection

$\Omega=$ maximum growth rate

\section{Subscripts}

c Combustion gas

d Droplets

$l \quad$ Liquid

rel Relative 


\section{REFERENCES}

(1) Ozturk, A.; Cetegen, B. M. Experiments on Ceramic Formation from Liquid Precursor Spray Axially Injected into an Oxy-Acetylene Flame. Acta Mater. 2005, 53, 5203.

(2) Chen, D.; Jordan, E. H.; Gell, M. The Solution Precursor Plasma Spray Coatings: Influence of Solvent Type. Plasma Chem. Plasma Process. 2010, 30, 111.

(3) Killinger, A.; Gadow, R.; Mauer, G.; Guignard, A.; Vaben, R.; Stöver, D.; Vaen, R.; Stöver, D.; Vaßen, R.; Stöver, D.; et al. Review of New Developments in Suspension and Solution Precursor Thermal Spray Processes. J. Therm. Spray Technol. 2011, $20,677$.

(4) Fauchais, P.; Joulia, A.; Goutier, S.; Chazelas, C.; Vardelle, M.; Vardelle, A.; Rossignol, S. Suspension and Solution Plasma Spraying. J. Phys. D. Appl. Phys. 2013, 46, 224015.

(5) Gozali, E.; Mahrukh, M.; Gu, S.; Kamnis, S. Numerical Analysis of Multicomponent Suspension Droplets in High-Velocity Flame Spray Process. J. Therm. Spray Technol. 2014, 23,940 .

(6) Whitlow, J. D.; Lefevbre, A. H. Effervescent Atomizer Operation and Spray Characteristics. At. Sprays 1993, 3, 137.

(7) Liu, L.; Fu, M.; Wu, J. The Distribution of SMD Downstream the Discharge Orifices of Effervescent Atomizers. J. Eng. Thermophys. 2001, 22, 653.

(8) Qian, L.; Lin, J.; Xiong, H. A Fitting Formula for Predicting Droplet Mean Diameter for Various Liquid in Effervescent Atomization Spray. J. Therm. Spray Technol. 2010, 19, 586.

(9) Castleman, R. A. The Mechanism of the Atomization of Liquids. Bur. Stand. J. Res. 1930, 6, 369.

(10) Lasheras, J. C.; Villermaux, E.; Hopfinger, E. J. Break-up and Atomization of a Round Water Jet by a High-Speed Annular Air Jet. J. Fluid Mech. 1998, 357, 351.

(11) Lefebvre, A. H.; Wang, X. F.; Martin, C. A. Spray Characteristics of Aerated-Liquid Pressure Atomizers. J. Propuls. Power 1988, 4, 293.

(12) Roesler, T. C.; Lefebvre, A. H. Studies on Aerated-Liquid Atomization. Int. J. Turbo Jet Engines 1989, 6, 221.

(13) Qian, L.; Lin, J.; Xiong, H. Simulation of Droplet-Gas Flow in the Effervescent Atomization Spray with an Impinging Plate. Chinese J. Chem. Eng. 2009, 17, 8.

(14) Sovani, S. D.; Sojka, P. E.; Lefebvre, A. H. Effervescent Atomization. Prog. Energy Combust. Sci. 2001, 27, 483.

(15) Qian, L.; Lin, J. Modeling on Effervescent Atomization: A Review. Sci. China Physics, Mech. Astron. 2011, 54, 2109.

(16) Jedelsky, J.; Jicha, M.; Slama, J.; Otahal, J. Development of an Effervescent Atomizer for Industrial Burners. Energy and Fuels 2009, 23, 6121.

(17) Jedelsky, J.; Otahal, J.; Jicha, M. Effervescent Atomizer : Influence of the Internal Geometry on Atomization Performance. In 21th ILASS - Europe; 2007; pp 1-6. 
(18) Jedelsky, J.; Landsman, M.; Jicha, M.; Kuritka, I. Effervescent Atomizer: Influence of the Operation Conditions and Internal Geometry on Spray Structure; Study Using PIV-PLIF. In ILASS, Italy; 2008; pp 8-10.

(19) Lund, M. T.; Sojka, P. E.; Lefebvre, A. H.; Gosselin, P. G. Effervescent Atomization at Low Mass Flow Rates. Part I: The Influence of Surface Tension. At. Sprays 1993, 3, 77.

(20) Qian, L.; Lin, J.; Xiong, H.; Leung Chan, T. Theoretical Investigation of the Influence of Liquid Physical Properties on Effervescent Atomization Performance. J. Fluids Eng. 2011, $133,101205$.

(21) Lin, J.; Qian, L.; Xiong, H. Relationship between Deposition Properties and Operating Parameters for Droplet onto Surface in the Atomization Impinging Spray. Powder Technol. 2009, 191, 340 .

(22) Esfarjani, S. A.; Dolatabadi, A. A 3D Simulation of Two-Phase Flow in an Effervescent Atomizer for Suspension Plasma Spray. Surf. Coatings Technol. 2009, 203, 2074.

(23) Esfarjani, S. A. Numerical Simulation of Two-Phase Flow in an Effervescent Atomizer for Nano-Suspension Spray, Master's thesis, Concordia University, 2007.

(24) Xiong, H.-B. H. B.; Qian, L.-J. L. J.; Lin, J. Z. J.-Z. Simulation of Effervescent Atomization and Nanoparticle Characteristics in Radio Frequency Suspension Plasma Spray. J. Therm. Spray Technol. 2012, 21, 226.

(25) Fung, M. C.; Inthanvong, K.; Yang, W.; Tu, J. Experimental and Numerical Modelling of Nasal Spray Atomisation. In Ninth International Conference on CFD in the Minerals and Process Industries; Melbourne, 2012; pp 1-6.

(26) Chen, D.; Jordan, E. H.; Gell, M. Solution Precursor High-Velocity Oxy-Fuel Spray Ceramic Coatings. J. Eur. Ceram. Soc. 2009, 29, 3349.

(27) Basu, S.; Cetegen, B. M. Modeling of Liquid Ceramic Precursor Droplets in a High-Velocity Oxy-Fuel Flame Jet. Acta Mater. 2008, 56, 2750.

(28) Cetegen, B. M.; Basu, S. Review of Modeling of Liquid Precursor Droplets and Particles Injected into Plasmas and High-Velocity Oxy-Fuel (HVOF) Flame Jets for Thermal Spray Deposition Applications. J. Therm. Spray Technol. 2009, 18, 769.

(29) Li, Q.; Cai, T. M.; He, G. Q.; Hu, C. B. Droplet Collision and Coalescence Model. Appl. Math. Mech. 2006, 27, 67.

(30) Mahrukh, M.; Kumar, A.; Gu, S.; Kamnis, S. Computational Development of a Novel Aerosol Synthesis Technique for Production of Dense and Nanostructured Zirconia Coating. Ind. Eng. Chem. Res. 2016, 55, 7679.

(31) Mahrukh, M.; Kumar, A.; Gu, S. Experimental Study of the Effects of Using Different Precursor Concentrations, Solvent Types, and Injection Types on Solution Precursor HighVelocity Oxygen Fuel (HVOF) Nanostructured Coating Formation. Ind. Eng. Chem. Res. 2017, 56, 4957.

(32) Suryanarayana, C.; Prabhu, B. Synthesis of Nanostructured Materials by Inert-Gas Condensation Methods. In Nanostructured Materials: Processing, Properties, and Applications; Carl, C. K., Ed.; William Andrew, Inc., 2007; pp 47-90.

(33) Gröhn, A. J.; Pratsinis, S. E.; Antoni, S.-F.; Raffaele, M.; Wegner, K. Scale-up for Nanoparticle Synthesis by Flame Spray Pyrolysis: The High-Temperature Particle Residence 
Time. Ind. Eng. Chem. Res. 2014, 53, 10734.

(34)

Gröhn, A. J.; Pratsinis, S. E.; Wegner, K. Fluid-Particle Dynamics during Combustion Spray Aerosol Synthesis of ZrO2. Chem. Eng. J. 2012, 191, 491.

(35) Dongmo, E.; Wenzelburger, M.; Gadow, R. Analysis and Optimization of the HVOF Process by Combined Experimental and Numerical Approaches. Surf. Coatings Technol. 2008, 202, 4470 .

(36) Gu, S.; Eastwick, C. N.; Simmons, K. A.; McCartney, D. G.; McCartney, G.; McCartney, D. G. Computational Fluid Dynamic Modelling of Gas Flow Characteristics in a High-Velocity Oxy-Fuel Thermal Spray System. J. Therm. Spray Technol. 2001, 10, 461.

(37) Mahrukh, M. Computational Modelling of Thermal Spraying Processes, Cranfield University, 2016.

(38) Kruis, F. E.; Kusters, K. A.; Pratsinis, S. E.; Scarlett, B. A Simple Model for the Evolution of the Characteristics of Aggregate Particles Undergoing Coagulation and Sintering. Aerosol Sci. Technol. 1993, 19, 514.

(39) Li, C.; Yang, H.; Li, H. Effect of Gas Conditions on HVOF Flame and Properties of WC-Co Coatings. Mater. Manuf. Process. 1999, 14, 383.

(40) Li, C.; Wang, Y. Effect of Particle State on the Adhesive Strength of HVOF Sprayed Metallic Coating. J. Therm. Spray Technol. 2002, 11, 523.

(41) Wang, Y.; Li, C.; Yang, G. Effect of Flame Conditions on Abrasive Wear Performance of HVOF Sprayed Nanostructured WC-12Co Coatings. Trans. Nonferrous Met. Soc. China 2004, 14,72 .

(42) Mahrukh, M.; Kumar, A.; Gu, S. Effects of Angular Injection, and Effervescent Atomization on High-Velocity Suspension Flame Spray Process. Surf. Coat. Technol. 2016, 302, 368.

(43) Shannon, K. S.; Butler, B. W. A Review of Error Associated with Thermocouple Temperature Measurement in Fire Environments. Int. Wildl. Fire Ecol. 2003, 7.

(44) Kamnis, S.; Gu, S. Numerical Modelling of Propane Combustion in a High-Velocity Oxygen-fuel Thermal Spray Gun. Chem. Eng. Process. Process Intensif. 2006, 45, 246.

(45) Li, M.; Christofides, P. D. Modeling and Control of High-Velocity Oxygen-Fuel (HVOF) Thermal Spray: A Tutorial Review. J. Therm. Spray Technol. 2009, 18, 753.

(46) Li, M.; Christofides, P. D. Multi-Scale Modeling and Analysis of an Industrial HVOF Thermal Spray Process. Chem. Eng. Sci. 2005, 60, 3649.

(47) Li, M.; Christofides, P. D. Computational Study of Particle in-Flight Behavior in the HVOF Thermal Spray Process. Chem. Eng. Sci. 2006, 61, 6540.

(48) Gozali, E.; Kamnis, S.; Gu, S. Numerical Investigation of Combustion and Liquid Feedstock in High Velocity Suspension Flame Spraying Process. Surf. Coatings Technol. 2013, 228, 176.

(49) Zeoli, N.; Gu, S.; Kamnis, S. Numerical Modelling of Metal Droplet Cooling and Solidification. Int. J. Heat Mass Transf. 2008, 51, 4121.

(50) Tabbara, H.; Gu, S. A Study of Liquid Droplet Disintegration for the Development of Nanostructured Coatings. AIChE J. 2012, 58, 3533. 
(51) Mahrukh, M.; Kumar, A.; Gu, S.; Kamnis, S.; Gozali, E.; Kamnis, S.; Gozali, E. Modeling the Effects of Concentration of Solid Nanoparticles in Liquid Feedstock Injection on HighVelocity Suspension Flame Spray Process. Ind. Eng. Chem. Res. 2016, 55, 2556.

(52) Magnussen, B. F.; Hjertager, B. H. On Mathematical Models of Turbulent Combustion with Special Emphasis on Soot Formation and Combustion. In 16th Symposium on Combustion.The Combustion Institute; 1976; Vol. 16, pp 719-729.

(53) Kuo, K. K. Principles of Combustion, 2nd ed.; John Wiley \& Sons, Inc., 1986.

(54) Fukumoto, K.; Ogami, Y. Simulation of CO-H$-\mathrm{H}_{2}$ Air Turbulent Nonpremixed Flame Using the Eddy Dissipation Concept Model with Lookup Table Approach. J. Combust. 2012, 2012, 1.

(55) Dongmo, E.; Gadow, R.; Killinger, A.; Wenzelburger, M. Modeling of Combustion as Well as Heat, Mass, and Momentum Transfer during Thermal Spraying by HVOF and HVSFS. $J$. Therm. Spray Technol. 2009, 18, 896.

(56) Gozali, E.; Mahrukh, M.; Gu, S.; Kamnis, S. Numerical Investigation on Effects of Nanoparticles on Liquid Feedstock Behavior in High-Velocity Oxygen Fuel (HVOF) Suspension Spraying. Surf. Coatings Technol. 2015, 280, 370.

(57) Gröhn, A. J.; Buesser, B.; Jokiniemi, J. K.; Pratsinis, S. E. Design of Turbulent Flame Aerosol Reactors by Mixing-Limited Fluid Dynamics. Ind. Eng. Chem. Res. 2011, 50, 3159.

(58) Torabmostaedi, H.; Zhang, T.; Foot, P.; Dembele, S.; Fernandez, C. Process Control for the Synthesis of $\mathrm{ZrO}_{2}$ Nanoparticles Using FSP at High Production Rate. Powder Technol. 2013, $246,419$.

(59) Torabmostaedi, H.; Zhang, T. Computational Study of the Effect of Processing Parameters on the Formation and Growth of $\mathrm{ZrO}_{2}$ Nanoparticles in FSP Process. Chem. Eng. Process. Process Intensif. 2014, 78, 1.

(60) Kamnis, S. C. Development of Multiphase and Multiscale Mathematical Models for Thermal Spray Process, PhD thesis, Aston University, 2007.

(61) Ansys Fluent Theory Guide. V14.5. Ansys, Inc. 2012, pp 1-735.

(62) Kamnis, S.; Gu, S. 3-D Modelling of Kerosene-Fuelled HVOF Thermal Spray Gun. Chem. Eng. Sci. 2006, 61, 5427.

(63) Gozali, E.; Kamnis, S.; Gu, S. Analysis of Liquid Feedstock Behavior in High-Velocity Suspension Flame Spraying for the Development of Nanostructured Coatings. In Proceedings of the International Thermal Spray Conference; 2013; pp 418-423.

(64) Jadidi, M.; Moghtadernejad, S.; Dolatabadi, A. A Comprehensive Review on Fluid Dynamics and Transport of Suspension/liquid Droplets and Particles in High-Velocity Oxygen-Fuel (HVOF) Thermal Spray. Coatings 2015, 5, 576.

(65) Launder, B. E.; Spalding, D. B. Lectures in Mathematical Models of Turbulence; Academic Press: London, 1972.

(66) Stephen, B. P. Turbulent Flows; Cambridge University Press, 2001.

(67) Senecal, P. K.; Schmidt, D. P.; Nouar, I.; Rutland, C. J.; Reitz, R. D.; Corradini, M. L. Modeling High-Speed Viscous Liquid Sheet Atomization. Int. J. Multiph. Flow 1999, 25, 1073.

(68) Dombrowski, N.; Hooper, P. C. The Effect of Ambient Density on Drop Formation in Sprays. 
Chem. Eng. Sci. 1962, 17, 291.

(69) Weber, C. Zum Zerfall Eines Flüssigkeitsstrahles. J. Appl. Math. Mech. / Zeitschrift für Angew. Math. und Mech. 1931, 11, 136.

(70) Rampon, R.; Filiatre, C.; Bertrand, G. Suspension Plasma Spraying of YPSZ Coatings: Suspension Atomization and Injection. J. Therm. Spray Technol. 2008, 17, 105.

(71) O’Rourke, P. J. Collective Drop Effects on Vaporizing Liquid Sprays, Princeton University, 1981.

(72) Henninger, H. B.; Reese, S. P.; Anderson, A. E.; Weiss, J. A. Validation of Computational Models in Biomechanics. Part H. J. Eng. Med. 2010, 224, 801.

(73) Gozali, E.; Kamnis, S.; Gu, S. Numerical Investigation of Combustion and Liquid Feedstock in High-Velocity Suspension Flame Spraying Process. Surf. Coatings Technol. 2013, 228, 176.

(74) Stahle, P.; Schuchmann, H. P.; Gaukel, V.; Staahle, P.; Schuchmann, H. P.; Gaukel, V. Performance and Efficiency of Pressure-Swirl and Twin-Fluid Nozzles Spraying Food Liquids with Varying Viscosity. J. Food Process Eng. 2017, 40, 1.

(75) Jedelsky, J.; Jicha, M. Energy Conversion during Effervescent Atomization. Fuel 2013, 111, 836.

(76) Wang, X. F.; Chin, J. S.; Lefebvre, A. H. Influence of Gas-Injector Geometry on Atomization Performance of Aerated-Liquid Nozzles. Int. J. Turbo Jet Engines 1989, 6, 271. 


\section{LIST OF FIGURES:}

Figure 1. Representation of the SPTS process for nanoparticles formation from ${ }^{31}$

Figure 2. Representation of precursor injection into the $\mathrm{CH}-2000 \mathrm{HVOF}$ torch (a) plain-orifice nozzle (N1), (b) angular injection nozzle (N2), (c) effervescent atomization nozzle (N3), (d) crosssection view of effervescent-type nozzle (N3) ${ }^{31,37,42}$

Figure 3. Axisymmetric, two-dimensional grids for (a) spray atomization in atmosphere for model validation (b) spray atomization in $\mathrm{CH}-2000 \mathrm{HVOF}$ torch application

Figure 4. Graphical comparison of the present results with the work of Liu et al., $2001^{7}$ and Qian et al., $2011^{15,20}$ (a) GLR=0.067, (b) GLR=0.090, (c) GLR=0.132, (d) GLR=0.176 ${ }^{37,42}$ (e-f) The coefficients of determination (R2) comparing CFD-SMD (present work) with experimental SMD values of Liu et al. ${ }^{7}$

Figure 5. Thermocouple temperature measurements and CFD temperature predictions of the $\mathrm{CH}$ 2000 HVOF flame with injection of different solvent solutions (using nozzle N3)

Figure 6. Comparison of SMD at varying GLR with $\mathrm{Q}_{\mathrm{gas}}=81 / \mathrm{min}, \mathrm{Q}_{\text {liquid }}=200 \mathrm{ml} / \mathrm{min}(\bullet-)$, $100 \mathrm{ml} / \mathrm{min}(-)$, and $50 \mathrm{ml} / \mathrm{min}(-)$ for (a) Water spray in atmosphere and (b) Ethanol spray in CH-2000 torch.

Figure 7. Variations in SMD with different GLR along the axial direction in the atmospheric spray [The blue dashed lines are for the $\mathrm{LFR}=50 \mathrm{ml} / \mathrm{min}$, the red dotted lines $\mathrm{LFR}=100 \mathrm{ml} / \mathrm{min}$, and the solid black lines for the $\mathrm{LFR}=200 \mathrm{ml} / \mathrm{min}]$.

Figure 8. Comparison of $\mathrm{SMD}$ at constant $\mathrm{GLR}=0.182$ and $\mathrm{P}_{\mathrm{inj}}=0.7 \mathrm{MPa}$ with various nozzle exit diameters $\left(D_{\text {inj }}\right)$ at different operating pressures (a) Water spray in the atmosphere and (b) Ethanol spray in $\mathrm{CH}-2000$ torch.

Figure 9. Comparison of Weber number and SMD, at constant $P_{\text {inj }}=0.7 \mathrm{MPa}, \mathrm{GLR}=0.182$, and $\mathrm{D}_{\mathrm{inj}}=1.5 \mathrm{~mm}$, for different solvents sprayed in (a) atmosphere, (b, c) CH-2000 torch

Figure 10. Comparison of SMD using P-E solvent injected at constant $P_{\text {inj }}=0.7 \mathrm{MPa}, \mathrm{GLR}=0.182$, and with varied nozzle types (a) Contours plot, and (b) graphical representation. 


\section{For Table of Contents Only}

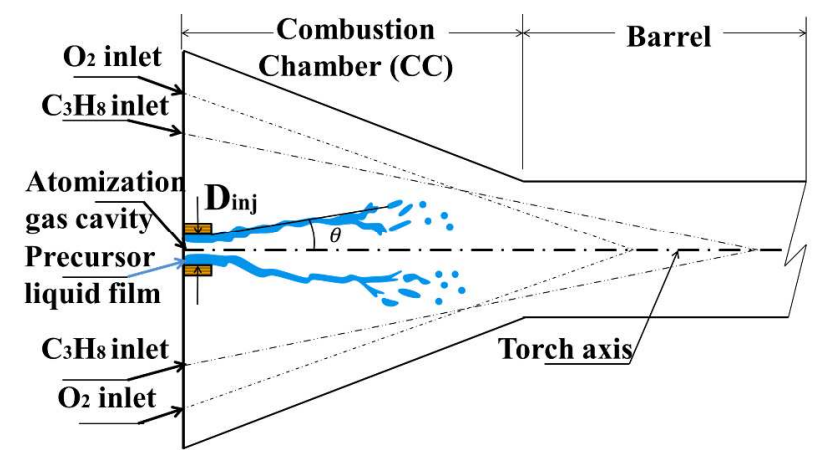

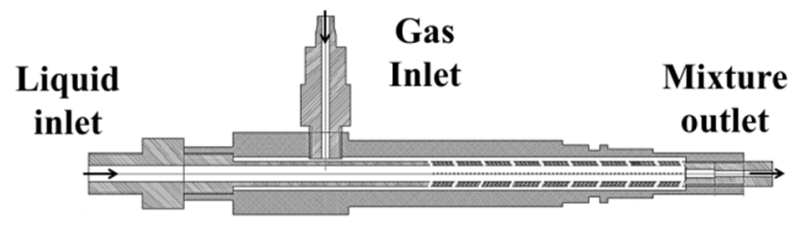

15

16

17

18

19

20

21

22

23

24

25

26

27

28

29

30

31

32

33

34

35

36

37

38

39

40

41

42

43

44

45

46

47

48

49

50

51

52

53

54

55

56

57

58

59

60 